\title{
¿UN RÉGIMEN ESPECIAL PARA LOS TRATADOS DE DERECHOS HUMANOS DENTRO DEL DERECHO INTERNACIONAL? \\ RESERVAS Y DENUNCIAS DE TRATADOS DE DERECHOS HUMANOS
}

\section{Carlos LóPEZ HURTADo*}

RESUMEN: El debate se centra en si deben o no los tratados de derechos humanos poseer un régimen especial dentro del derecho internacional. Para esto, el autor aborda los procedimientos de denuncia y reserva plasmados en las Convenciones de Viena, que ha sido el instrumento en los que ambas partes centran la mayoría de sus argumentos. Los que se inclinan por un régimen especial mencionan que las convenciones de Viena no poseen los elementos suficientes para ser aplicados a los tratados de derechos humanos, pues en estos no se habla de un consentimiento de voluntades, de acuerdo con la práctica internacional, sino de normas de conducta, donde la pretensión principal es el orden publico común. Los que dicen que no, mencionan que las Convenciones de Viena se crearon precisamente con el espíritu de ser aplicables a todo tipo de tratados, por lo que es innecesario ubicar a los tratados de derechos humanos en un régimen especial, pues eso sería como ubicar también en otra esfera a los tratados del medio ambiente, de desarme, etcétera.
ABSTRACT: The debate is focused on whether human rights treaties should posses a special regime in international law. For this purpose the author discusses the denunciation and reservation proceedings contained in the Vienna Conventions, the instruments upon which both parties focus most of their arguments. Those in favour of a special regime argue that the Vienna Conventions do not posses enough elements to be applied to human rights treaties, since the latter make no reference to a will agreement, consistently with the international practice, but to norms of conduct where the main claim is the common public order. Those against hold that the Vienna Conventions were created precisely with the aim of being applied to any kind of treaty, thus being unnecessary to place human rights treaties under a special regime, since this would be like placing environment, disarmament, etc., treaties under a special regime as well.

* Candidato a doctor en relaciones internacionales (derecho internacional público), Institut Universitaire de Hautes Études Internationales, Ginebra, Suiza. 
SUMARIO: I. Introducción. II. Las reservas a los tratados de derechos humanos. III. Denuncia de los tratados de derechos humanos. IV. Los tratados de derechos humanos como tratados de naturaleza especial. V. Conclusiones. VI. Bibliografía.

\section{INTRODUCCIÓN}

La idea de que los tratados de derechos humanos son de una naturaleza especial, con una estructura interna de obligaciones esencialmente diferente de aquellos otros tratados basados en la reciprocidad, ha sido expresada en múltiples decisiones de la Corte Europea de Derechos Humanos y de la Comisión Europea de Derechos Humanos, así como, más recientemente, en las decisiones de la Corte Interamericana de Derechos Humanos y del Comité de Derechos Humanos del Pacto de Derechos Civiles y Políticos. Esta idea ha llevado a algunos académicos y organismos a proponer un régimen de derecho internacional especial o diferente para este tipo de tratados en atención a su naturaleza o estructura que se pretende diferente al resto de tratados. Con esta pretensión lo que está en juego, como se verá con detalle más adelante, es no sólo la unidad o diversidad de regímenes dentro del derecho de los tratados, establecido por la práctica internacional y plasmado, en gran parte, en las Convenciones de Viena sobre el derecho de tratados de 1969 y 1986, sino el fundamento mismo del derecho internacional tal como se ha entendido hasta el momento: el principio del consentimiento a asumir obligaciones internacionales como base del derecho internacional interestatal basado en soberanías yuxtapuestas.

La práctica reciente de los órganos conformados en virtud de ciertos tratados de derechos humanos para la supervisión de los mismos, así como la reacción de algunos Estados hacia esa práctica, en materia de reservas y denuncias a dichos tratados, ha motivado un gran interés en el medio académico y también al interior de organismos internacionales especializados a nivel regional y universal. Es así como la Comisión de Derecho Internacional, órgano principal de las Naciones Unidas para la codificación y desarrollo del derecho internacional, al igual que la Subcomisión de Promoción y Protección de los Derechos Humanos de Naciones Unidas, entre otros, han incluido como parte de sus trabajos el debate y estudio del régimen jurídico internacional aplicable a los tratados de de- 
rechos humanos, notablemente en cuanto al tema específico de las reservas a dichos tratados.

El objetivo del presente artículo es analizar, de manera sucinta, dentro de los márgenes de espacio de un artículo de esta naturaleza, los argumentos que preconizan un régimen especial en el derecho internacional para los tratados de derechos humanos, con la finalidad de echar algunas luces sobre el tema, que contribuyan a esclarecer los términos del debate. Asumimos, desde un principio, que el debate está y permanecerá abierto por un buen tiempo, y que el derecho internacional, al menos sobre los temas que se analizarán, está en permanente evolución, por lo cual no resulta pertinente arribar a conclusiones definitivas por el momento. Nuestro análisis se centrará en dos aspectos en los cuales la idea de un régimen especial para los tratados de derechos humanos ha sido más desarrollada y en los cuales ha habido ya un debate sustantivo. Éstos son, por un lado, las reservas a los tratados de derechos humanos y, por el otro, el tema de la denuncia de los mismos, tema, este último, en el que incluimos el retiro de declaraciones de aceptación de la competencia de un órgano jurisdiccional en materia de derechos humanos establecido en virtud de un tratado; además, prestamos una atención especial a la más reciente jurisprudencia en los temas en cuestión. Una tercera parte abordará la tesis de los tratados de derechos humanos como tratados de naturaleza especial, que es la base de las propuestas sobre un régimen jurídico especial en materia de reservas y denuncias para estos tratados. Por último, se ofrecerán algunas conclusiones parciales, en el entendido de que el debate permanecerá abierto todavía.

\section{LAS RESERVAS A LOS TRATADOS DE DERECHOS HUMANOS}

En diciembre de 1999 el Comité de Derechos Humanos (el Comité), órgano encargado de la supervisión del Pacto Internacional de Derechos Civiles y Políticos (el Pacto), adoptó una decisión ${ }^{1}$ declarando admisible una comunicación individual hecha en el marco del primer protocolo $\mathrm{Fa}$ cultativo del Pacto de Derechos Civiles y Políticos (el Protocolo o primer protocolo). En esta decisión, el Comité puso en práctica su anunciada

1 Caso Rawle Kennedy (decisión sobre admisibilidad). Decisión del Comité de Derechos Humanos emitida a tenor del Protocolo Facultativo del Pacto Internacional de Derechos Civiles y Políticos. Comunicación 845/1999, 31 de diciembre de 1999, CCPR/C/67/D/845/1999. 
doctrina en materia de reservas al Pacto declarando inválida la reserva formulada por el Estado parte en el Protocolo, Trinidad y Tobago, y además admisible la petición individual en cuestión dejando de lado la reserva y considerando al Estado parte obligado por el Protocolo en su conjunto sin el beneficio de la reserva declarada inválida. En su razonamiento, el Comité consideró que la reserva en cuestión era incompatible con el objeto y fin del Protocolo como tratado de derechos humanos.

La decisión del Comité marca el más reciente episodio en un debate ya bastante largo, pero no acabado en el derecho internacional, y que tiene relevancia no sólo para el futuro de los tratados de derechos humanos y la eventual protección de éstos, sino también para la misma concepción del derecho internacional como derecho interestatal basado en el consentimiento de los Estados. La decisión del Comité fue adoptada después de un intenso debate al interior de éste y con la eventual presentación, por algunos miembros del Comité, de una opinión disidente que fue anexada al texto de la decisión. Esta opinión disidente refleja, en lo esencial, una corriente crítica o escéptica sobre el tema que se verá más adelante. ${ }^{2}$

En las secciones siguientes vamos a presentar y analizar, a partir de los argumentos en el caso Kennedy y otros presentados con anterioridad en el debate, los elementos más importantes del debate.

\section{El modelo de la Convención de Viena de 1969}

En una discusión sobre el régimen de reservas a tratados es imprescindible comenzar con una sucinta revisión del régimen establecido en las Convenciones de Viena de 1969 y 1986.

Las normas sobre reservas se encuentran en los artículos 19 a 23 de la Convención de Viena sobre el Derecho de los Tratados. ${ }^{3}$

2 Idem, voto particular disidente de los miembros del Comité, Nisuke Ando, Prafulachandra N. Bhagwati, Eckart Klein y David Kretzmer. CCPR/C/67/D/845/1999, 31 de diciembre de 1999. Entre las sorpresas de la decisión del Comité figura también el voto particular concurrente del miembro del Comité, Louis Henkin, quien simplemente expresa: "Estoy de acuerdo con el resultado". Esta lacónica expresión reflejaría un cambio radical en el pensamiento del profesor Henkin, quien en el pasado ha sido uno de los más destacados defensores de la posición que niega a los tratados de derechos humanos una naturaleza especial. Ver al respecto Henkin, Louis, The Age of Rights, Nueva York, Oxford, Columbia University Press, 1990.

3 Convención de Viena sobre el Derecho de los Tratados, 1155 United Nations Treaty Series, 331. El artículo 19 establece:

Un Estado puede formular una reserva en el momento de firmar, ratificar, aceptar, o aprobar un tratado o adherirse al mismo, a menos: 
Los artículos 20 y 21 establecen un complejo sistema de aceptaciones y objeciones por parte de los otros Estados parte en el tratado que tiene como objeto establecer un sistema de control de validez de la reserva formulada por una de las partes. Así, un Estado puede aceptar u objetar a una reserva formulada por otro Estado, y en el caso de objetarla puede declarar su deseo de que el tratado en su conjunto no entre en vigor entre él y el Estado que formuló la reserva. La consecuencia jurídica de este juego de aceptaciones y objeciones es la modulación del conjunto de obligaciones y derechos para cada una de las partes en el tratado, tanto para el Estado que formula la reserva como para los que aceptan u objetan. Así, si la reserva es aceptada, el tratado entra en vigor entre las partes inter se en la medida en que lo define la reserva formulada. De esta manera, si la reserva es objetada, el tratado puede entrar o no en vigor entre las partes inter se. Si el tratado entra en vigor, las disposiciones a que se refiera la reserva objetada no se aplicarán entre las dos partes en la medida determinada por la reserva. Según este modelo, una reserva objetada por considerarse no compatible con el objeto y propósito del tratado tiene el efecto de excluir las disposiciones a que se refiere o, si lo prefiere la parte objetora, determinar la no participación en el tratado del Estado que formuló la reserva vis a vis la parte objetora.

Es este régimen de reservas plasmado en las Convenciones de Viena de 1969 y 1986 el que ha sido cuestionado recientemente desde varios ángulos. En especial, se considera que este régimen es inadecuado para efectos de evaluar la admisibilidad de las reservas a los tratados de derechos humanos. Con énfasis distintos, algunos autores ${ }^{4}$ han observado que

a) Que la reserva esté prohibida por el tratado;

b) Que el tratado disponga que únicamente pueden hacerse determinadas reservas, entre las cuales no figure la reserva de que se trate; $o$

c) Que en los casos no previstos en los apartados a) y b), la reserva sea incompatible con el objeto y fin del tratado. El artículo 19 establece la norma sustantiva en la materia. Según este artículo, la formulación de reservas a tratados, cualquiera que sea su tipo o naturaleza, está, en principio, permitida, excepto si el propio tratado lo prohíbe, o permite sólo un determinado tipo de reservas dentro las cuales la reserva en cuestión no está incluida, o la reserva en cuestión es incompatible con el objeto y fin del tratado. Este artículo establece que, a falta de disposición expresa en el tratado, el criterio fundamental para evaluar la admisibilidad de una reserva es el objeto y fin del tratado.

4 Simma, Bruno, "From bilateralism to community interest in international law", Recueil des Cours de l'Académie de Droit International de La Haye, 1994-VI, vol. 250, pp. 219-384; Segundo Informe sobre las reservas a los tratados, preparado por Allan Pellet, relator especial, Comisión de Derecho Internacional, A/CN.4/477/Add.1 13 de junio de 1996 (será citado en adelante como Pellet, Allan, Segundo Informe). 
el régimen de Viena seíia incompleto en esta materia, mientras que otros ${ }^{5}$ consideran concluyentemente que este régimen no provee respuestas adecuadas en este campo.

$\mathrm{El}$ régimen de las Convenciones de Viena plasma convencionalmente la doctrina de la Corte Internacional de Justicia desarrollada en su Opinión Consultiva sobre las Reservas a la Convención contra el Genocidio de 1951.6 La opinión de la Corte constituyó un punto de quiebre en la evolución del régimen de reservas a tratados multilaterales dentro del derecho internacional. La Corte optó claramente por establecer un mecanismo flexible y general que, se esperaba, pudiera servir y adaptarse a la variada naturaleza y tipos de tratados en la práctica internacional, con la finalidad de permitir la más amplia participación de Estados en un tratado internacional que por sus objetivos humanitarios necesitaba de una participación universal. En concreto, la Corte Internacional de Justicia privilegió el principio de universalidad frente al principio de la integralidad de los tratados hasta entonces vigente (partidaria de conservar la integridad de las obligaciones dentro de los tratados).

El tema de las reservas a los tratados de derechos humanos que ahora nos ocupa no es pues nuevo, ya que estuvo a la base de la opinión consultiva de la Corte Internacional de Justicia en 1951 y había sido discutido ya mucho antes. ${ }^{7}$ Sin embargo, su actualidad hoy en día viene dada por un fenómeno particular que los redactores de las Convenciones de Viena no pudieron prever. Por un lado, la masiva adhesión de países a los tratados de derechos humanos ha hecho realidad, en cierta medida, la aspiración al universalismo contenida en la fórmula de Viena. Al mismo tiempo, los Estados han recurrido, al momento o adherirse a los tratados en cuestión, a la formulación de reservas que muchas veces limitan de manera importante el campo de aplicación y la efectividad del tratado y, por tanto, limitan también el efecto jurídico y político de tal universalidad. En tercer lugar, la práctica de los Estados y el desarrollo del derecho internacional en esta esfera han sido particularmente ricos en las décadas que han seguido a la adopción de la Convención de Viena de 1969. Cierta-

5 Ver la introducción de la juez Rosalyn Higgins al trabajo colectivo Human Rights as general norms and a state's right to opt out. Reservations and objections to human rights conventions, Chinkin, Christine (et al.) British Institute of Comparative and International Law, London, 1997.

6 Reservations to the Convention on the Prevention and Punishment of the Crime of Genocide Advisory Opinion, 28 May 1951, ICJ Reports 1951 p. 15.

7 Pellet, Allan, Segundo Informe, cit., nota 4. 
mente, el contexto político internacional ha sido favorable a una expansión de la protección a los derechos humanos, lo cual se ha acentuado después del fin de la guerra fría. En este contexto, el elemento más importante, y quizá crucial para los debates actuales, es la práctica de los órganos de supervisión y vigilancia de los más importantes tratados de derechos humanos.

\section{La práctica de los organismos supervisores de los tratados de derechos humanos}

Las insuficiencias del régimen de reservas de la Convención de Viena han sido subrayadas en múltiples ocasiones por algunos órganos establecidos en virtud de ciertos tratados de derechos humanos con el mandato de supervisar su cumplimiento por los Estados parte y, sobre todo a nivel regional, con el mandato de recibir y examinar comunicaciones o peticiones individuales de nacionales de los Estados parte que consideran que sus derechos han sido violados.

La práctica y jurisprudencia de estos órganos sobre la materia han evolucionado en el tiempo desde una posición cauta y abstencionista hacia una actitud más asertiva en tiempos recientes. Así, en 1982 un órgano internacional adoptó, por primera vez, una posición sobre la validez o invalidez de una reserva formulada por un Estado parte en un tratado de derechos humanos. En ese año la Comisión Europea de Derechos Humanos consideró que la reserva bajo escrutinio en el caso Temeltasch era inválida. En 1988, la Corte Europea de Derechos Humanos, siguiendo el ejemplo de la Comisión Europea, declaró en el caso Belilos contra Suiza que una declaración interpretativa formulada por este país era, en realidad, una reserva que no estaba permitida por la Convención Europea. ${ }^{8}$ En ambos casos, estos órganos no sólo declararon las reservas en cuestión ilícitas, sino que además concluyeron que el conjunto del tratado, incluyendo la parte materia de la reserva declarada ilícita, estaba en vigor para el Estado parte. Las instituciones europeas han aplicado esta doctrina en muchas ocasiones desde entonces. Por su parte, la Corte Interamericana

8 Belilos $v$. Switzerland, European Court of Human Rights, Judgement of 29 April 1988, Series A, N 132. Ver también, Temeltasch v. Switzerland, Application N 9116/80, Report of 5 May 1982, Decisions and Reports of the European Commission of Human Rights; Loizidou v. Turkey (Preliminary Objections) European Court of Human Rights, Judgement of 23 March 1995 Series A N 310 , p. 25. 
también ha desarrollado una doctrina paralela siguiendo los pasos de la Corte Europea. ${ }^{9}$

A nivel universal, un punto de vista similar ha sido desarrollado por el Comité de Derechos Humanos, al menos a nivel teórico, con su Observación General 24. En este comentario por primera vez un órgano de naturaleza universal adopta una visión amplia de su propia competencia para evaluar la validez de una reserva y anuncia su propia doctrina de la "separabilidad", ya practicada por los órganos regionales. ${ }^{10}$

La Observación General 24 ha sido objeto de fuertes reacciones de parte de algunos países (entre ellos Estados Unidos, Francia y Gran Bretaña), ${ }^{11}$ las cuales han brindado importante material de discusión. ${ }^{12}$ En este contexto, el debate sobre las reservas a los tratados de derechos humanos ha entrado en la agenda de trabajo de la Comisión de Derecho Internacional (CDI), la cual ha nombrado como relator especial sobre el tema al profesor Allan Pellet. En 1996 el profesor Pellet presentó un detallado y acucioso segundo informe ${ }^{13}$ que discute, de manera esclarecedora, los términos del debate actual y ha permitido a la CDI adoptar, a propuesta del relator especial, un documento de conclusiones preliminares ${ }^{14}$ y decidir la elaboración de una guía para la práctica estatal, la cual está aún en preparación. El tema ha sido también propuesto y debatido en la Subcomisión de Protección y Promoción de Derechos Humanos, la cual ha nombrado a un relator especial encargado de elaborar un estudio completo sobre el tema específico de reservas a los tratados de derechos humanos. ${ }^{15}$

9 El efecto de las reservas sobre la entrada en vigor de la Convención Americana de Derechos Humanos (artículos 74 y 75), Opinión Consultiva OC-2/82 Corte Interamericana de Derechos Humanos, 24 de setiembre de 1982, serie A N 2 ; Restricciones a la pena de muerte (artículos 4.2 y 4.4. de la Convención), Opinión Consultiva OC-3/83 Corte Interamericana de Derechos Humanos, 8 de septiembre de 1983, serie A N 3.

10 Observación General 24 CCPR/C/21/Rev.1/Add. 6, 11 de noviembre de 1994, reproducido en Informe del Comité de Derechos Humanos a la Asamblea General, Actas Oficiales de la Asamblea General, 50va sesión, Suplemento 40 (A/50/40).

11 Reproducido en idem. (A/50/40) vol. I Anexo V, y en Informe del Comité de Derechos Humanos a la Asamblea General, Actas Oficiales de la Asamblea General, 51 va sesión, Suplemento 40 (A/51/40) Anexo VI.

12 Ver de manera general Salado, Ana, "Estudio sobre el comentario general número 24 del Comité de Derechos Humanos", Anuario de Derecho Internacional, XIV, 1998, Universidad de Navarra, pp. 589-633; Higgins, Rosalyn, cit., nota 5.

13 Pellet, Allan, Segundo Informe, cit., nota 4.

14 Preliminary Conclusions of the International Law Commission on Reservations to normative multilateral treaties including human rights treaties. Report of the International Law Commission to the General Assembly on its forty-ninth session, 12 May-18 July 1997. G.A.O.R. fifty-second session Supplement 10 (A/52/10), pp. 126-127.

15 Resolución 1999/27 Subcomisión de Promoción y Protección de los Derechos Humanos. In- 
En este contexto, el caso Kennedy viene a agregar, en diciembre de 1999, un elemento nuevo en el debate. Hasta entonces la práctica de los órganos de nivel universal se había limitado a la Observación General 24 del Comité de Derechos Humanos, y a algunas apreciaciones de este Comité en el contexto de los exámenes de informes presentados por los Estados parte en el Pacto. Con el caso Kennedy, por primera vez, un órgano de nivel universal no sólo evalúa la licitud de una reserva y la declara inválida, sino que además la separa del resto del consentimiento del Estado parte, concluyendo que éste se encuentra obligado bajo los términos del protocolo facultativo como un todo sin tomar en consideración la reserva.

\section{El caso Kennedy y el estado del debate sobre reservas a tratados de derechos humanos}

Trinidad y Tobago, que se había adherido originalmente al primer Protocolo en 1980, lo denunció el 26 de mayo de 1998 para readherirse a él el mismo día, pero esta vez con una reserva que limita la competencia del Comité para conocer peticiones individuales relacionadas con individuos condenados a la pena capital. ${ }^{16}$ Las razones expuestas por Trinidad y Tobago para la formulación de su reserva tienen que ver con limitaciones de orden constitucional interno. Dada la jurisprudencia del Comité Judicial del Consejo Privado, con valor constitucional en el país, en el sentido de que en casos en que la ejecución de un condenado a muerte tenga lugar

forme de la Subcomisión de Promoción y Protección de los Derechos Humanos sobre su 51 periodo de sesiones. E/CN.4/2000/2 10 de noviembre de 1999. Ha habido y hay otras iniciativas al respecto. El Comité de la Convención para la Eliminación de la Discriminación contra la Mujer sugirió la idea de pedir una Opinión Consultiva a la Corte Internacional de Justicia, y la junta de presidentes de los comités de supervisión de diversos tratados formuló recomendaciones pidiendo a los comités declarar inequívocamente la invalidez de las reservas que consideren que son incompatibles con el objeto y propósito del tratado respectivo. El debate ha sido llevado también a la Comisión de Derechos Humanos y a la propia Asamblea General, las cuales han adoptado la práctica de adoptar resoluciones periódicas sobre el tema. Por otro lado, la Comisión ha endosado recientemente la decisión de la Subcomisión de nombrar a un relator especial sobre el tema.

16 La reserva de Trinidad y Tobago, tal como es transcrita en el texto de la decisión sobre el caso kennedy, es como sigue:

“...Trinidad y Tobago vuelve a adherirse al Protocolo Facultativo del Pacto Internacional de Derechos Civiles y Políticos con una reserva respecto del artículo 1o. en el sentido que el comité de Derechos Humanos no será competente para recibir ni examinar comunicación alguna que tenga relación con los reclusos que estén condenados a pena de muerte respecto de cualquier asunto relacionado con su acusación, detención, procesamiento, condena, sentencia o ejecución de la pena de muerte a que se le hubiera condenado, ni con ningún asunto conexo" (párrafo 4.1). 
cinco años después de dictada la sentencia, habría razones para considerar que la demora constituye un castigo u otro trato inhumano o degradante, Trinidad y Tobago debía asegurarse de que la ejecución de las sentencias no supere dicho periodo de tiempo. La posibilidad de recurrir al Comité, por parte de individuos condenados a la pena de muerte, implicaría un retardo en la ejecución.

En el caso del señor Rawle Kennedy, un ciudadano cuyo caso estaría prima facie cubierto por la reserva formulada por Trinidad y Tobago al ser un preso condenado a la pena capital en espera de su ejecución, el Comité decidió que era competente para conocer el fondo a pesar de la reserva a la cual declaró incompatible con el objeto y fin del primer protocolo.

Para llegar a esta conclusión, el Comité estableció, primero, que de acuerdo con su propia Observación General 24, le corresponde a él mismo "interpretar y determinar la validez de las reservas hechas" al Pacto Internacional de Derechos Civiles y Políticos y a sus protocolos facultativos. Para ello, el Comité considera que el criterio fundamental, a falta de una provisión explícita dentro del Protocolo, es el señalado en la Convención de Viena sobre el Derecho de los Tratados y los principios del derecho internacional consuetudinario: el objeto y propósito del tratado. Se trataría de determinar si la reserva en cuestión es compatible con el objeto y propósito del Protocolo Facultativo, ${ }^{17}$ y ello determinará si la reserva tiene efecto legal o no y si el Comité tiene finalmente competencia en el caso o no.

Citando otra vez su observación general 24, el Comité concluyó: “...dado que el objeto y fin del primer Protocolo Facultativo es el de permitir que el Comité compruebe si el Estado respeta los derechos por los que se ha comprometido a velar, toda reserva que trate de impedir esto sería contraria al objeto y fin del primer Protocolo Facultativo, cuando no del Pacto". 18

Igualmente, el Comité consideró que la reserva en cuestión concede a un determinado grupo de ciudadanos, aquellos condenados a muerte, menor protección procesal que al resto de la población, y que por ello constituye una discriminación que infringe principios básicos del Pacto y sus protocolos, no pudiendo ser considerado compatible con el objeto y fin del protocolo facultativo. ${ }^{19}$

17 Caso Kennedy, op. cit. supra nota 1, párrafo 6.5.

18 Observación General 24, op. cit., nota 10, párrafo 13, citado en Caso Kennedy, párrafo 6.6 ( $\sin$ resaltar en el original).

19 Caso Kennedy, op. cit. supra nota 1, párrafo 6.7. 
Finalmente, el Comité extrae, muy lacónicamente, la conclusión final de su razonamiento: "La consecuencia es que el Comité no tiene impedimentos para examinar la presente comunicación con arreglo al Protocolo Facultativo".20

La decisión del Comité sobre admisibilidad en el caso Kennedy nos permite reseñar el estado de los debates y a la vez abordar algunos de los aspectos de la discusión desde el punto de vista del derecho internacional. Naturalmente, hay muchos puntos que son materia de consenso entre diversos sectores académicos mientras que otros son materia de encendido debate.

Entre aquellos elementos aludidos por el Comité en su decisión sobre admisibilidad en el caso Kennedy hay algunos principios del derecho internacional general ampliamente reconocidos. Se trata, en primer lugar, del principio de "la competencia de la competencia", por el cual un órgano jurisdiccional tiene la competencia para decidir sobre la amplitud y límites de su propia jurisdicción. ${ }^{21}$ Un segundo principio utilizado es más propio del derecho de los tratados, y es formulado en las Convenciones de Viena como el criterio fundamental para evaluar la validez de una reserva: el objeto y fin del propio tratado.

La doctrina del Comité en el sentido de considerarse competente para evaluar la validez de las reservas formuladas al Pacto y a sus protocolos no es nueva. Como se ha mencionado anteriormente, tanto la Corte Europea como la Interamericana la habían expresado mucho antes, y el propio Comité ya lo había anunciado en su Observación General 24. Aunque, en la opinión de algunos, la competencia de los órganos de supervisión en la evaluación de la validez de las reservas no es un tema de real controver$\mathrm{sia}^{22}$ éste genera importantes problemas jurídicos y no termina de ser aceptado por el conjunto de los Estados. No olvidemos que, según el régimen de Viena, son los otros Estados parte quienes tienen la tarea de evaluar la validez de una determinada reserva formulada por uno de los Estados parte en el tratado. Tampoco debe olvidarse que ningún tratado de derechos humanos ha dado expresamente poder a los órganos de supervisión para realizar dicha evaluación, aunque tampoco se les ha prohibido hacerlo. En este contexto, el propio Comité, y a su lado un número respe-

20 Idem.

21 Shihata, Ibrahim, The Power of the International Court to Determine its own Jurisdiction. Compétence de la compétence, The Hague, Martinus Nijhoff Publ., 1965.

22 Pellet, Allan, Segundo Informe, cit., nota 4, pp. 209-210. 
table de instituciones y académicos, han expresado la opinión de que la tarea en cuestión es, al menos, inadecuada para los Estados, ${ }^{23}$ afirmación que cuestiona las bases mismas del régimen de Viena.

A este respecto, podríamos decir que existe, en este momento, un creciente consenso en considerar que si bien la facultad para evaluar la validez de las reservas no está explícitamente establecida en los tratados constitutivos de estos órganos, ésta es una facultad implícita dentro de su mandato de supervisión del tratado en la medida en que es necesaria para que dichos órganos puedan cumplir su misión. ${ }^{24}$ En todo caso, y a pesar de que el régimen de Viena no asigna esa tarea sino a los Estados parte, nada impide llegar a la conclusión de que ambos métodos de control pueden perfectamente coexistir, aunque las consecuencias prácticas de dicho control presenten problemas que son difíciles de resolver. En efecto, dejando de lado pretensiones exclusivistas, las competencias de los órganos de supervisión en materia de evaluación de la validez de las reservas pueden coexistir con aquellas de los Estados según el régimen establecido en la Convención de Viena, sin contradecir a esta última. Y esto debido, fundamentalmente, a que el régimen de Viena guarda silencio sobre el punto $\mathrm{y}$, además, tal fórmula sería consistente con los principios generales del derecho internacional que otorgan a los órganos jurisdiccionales o de supervisión la "competencia para decidir sobre su propia competencia".

Ha sido el relator especial de la Comisión de Derecho Internacional (CDI) para el tema de reservas, profesor Pellet, quien más ha insistido sobre la fórmula de la coexistencia entre estos dos métodos de control, aunque su posición no refleja una opinión unánime al interior de la CDI. ${ }^{25}$ A pesar de la variedad de opiniones dentro de este órgano, en su conjunto la posición asumida en sus conclusiones preliminares aprobadas al término de la sesión de 1997 marcha en la dirección indicada. ${ }^{26}$

La decisión del Comité en el caso Kennedy refleja además otro consenso general: la aceptación del criterio del objeto y propósito del tratado, planteado en el régimen de Viena como aplicable de manera general, para

23 Ver Observación General 24, op. cit., nota 8, p. 18; Higgins, Rosalyn, op. cit., nota 5.

24 Pellet, Alan, Segundo informe, cit., nota 4, p. 211.

25 Las diversas posiciones se han expresado durante el debate del segundo informe del relator especial llevado a cabo durante la sesión de 1997. Report of the ILC on the work of its forty-ninth session, 12 May 18 July 1997. General Assembly, Official Records, 52a. session. Supp. 10 (A/52/10).

26 Los párrafos 5 y 6 de las Conclusiones Preliminares de la Comisión de Derecho Internacional sobre Reservas a Tratados Multilaterales Normativos, incluyendo Tratados de Derechos Humanos establecen: ibidem, p. 126. 
evaluar la validez de las reservas a tratados de derechos humanos (en este caso al Primer Protocolo). El hecho de que este criterio haya sido utilizado de manera reiterada en las decisiones de los órganos de derechos humanos, especialmente a nivel regional, evidencia su carácter de norma apropiada y universalmente aceptada.

Los elementos anteriores nos permiten obtener una primera conclusión. Al aceptar que los órganos de supervisión de tratados de derechos humanos tienen competencia para evaluar la validez de reservas estaríamos reconociendo implícitamente que el régimen de las Convenciones de Viena, que no contempla tal posibilidad ni la regula, es insuficiente en este respecto. Los redactores de las convenciones de Viena no pensaron en el papel que ciertos órganos creados por los tratados para su supervisión podrían eventualmente jugar. Hay, evidentemente, una laguna en el derecho de los tratados, la cual viene siendo llenada por la práctica de los órganos de supervisión de tratados de derechos humanos y constituye una verdadera contribución al desarrollo progresivo del derecho internacional.

Sin embargo, hay varios escollos de orden doctrinal y práctico que será necesario superar antes que la norma antedicha quede totalmente consagrada en el derecho internacional. Algunos de ellos han sido señalados por la señora Hampson, experta independiente de la Subcomisión de Naciones Unidas para la Promoción y Protección de los Derechos Humanos. ${ }^{27}$ Hampson señala, en primer lugar, que el propio régimen de Viena muestra ya ciertas inconsistencias, como por ejemplo el hecho de que una misma reserva podría ser evaluada por dos Estados diferentes de manera también diferente. Uno o algunos de los Estados pueden aceptar la reserva como válida, mientras que otro, u otros, pueden objetarla como inválida, siempre tomando como medida la compatibilidad con el objeto y propósito del tratado. ${ }^{28}$ Lo mismo podría suceder en el caso de que un órgano supervisor adopte una posición declarando la invalidez de una reserva determinada y, al mismo tiempo, algunos o la mayoría de los Estados parte en el tratado consideren que dicha reserva es totalmente válida. ${ }^{29}$ La cuestión es si tal diversidad de opiniones y evaluaciones sobre la compatibilidad de una determinada reserva con el objeto y propósito de un tratado

27 Reservations to human rights treaties. Working paper submitted by Ms. Françoise Hampson pursuant to Sub-commission decision 1998/113 (citado en adelante como Hampson, Françoise, Working paper, Sub-Commission on Prevention of Discrimination and Protection of Minorities E/CN.4/Sub.2/1999/28 28 June 1999).

28 Ibidem, p. 11.

29 Ibidem, p. 22. 
son conciliables, y si tal diversidad no supondría una diferencia de interpretación tan radical que, al final, podría llegar a tener un impacto negativo sobre la implementación misma del tratado. La pregunta, que tiene una cierta importancia a nivel teórico, no presenta sin embargo mayor problema a nivel práctico. Volveremos sobre ello más adelante.

La decisión del Comité en el caso Kennedy presenta también un conjunto de elementos que son materia de encendida controversia en el ámbito del derecho internacional. El elemento central a este nivel es el paso crucial dado por el Comité al poner en práctica su doctrina acerca de la separabilidad de las reservas declaradas inválidas.

$\mathrm{Si}$ bien se puede hablar de un cierto consenso sobre la competencia que los órganos de supervisión tendrían para evaluar la validez de las reservas, sobre el tema de las consecuencias que deben derivarse de esa evaluación no hay más que posiciones firmemente discrepantes. Por un lado, los órganos de supervisión, como el Comité mismo en su decisión sobre el caso Kennedy, reivindican la facultad no sólo de evaluar una reserva y declararla inválida, sino también de considerarla como inexistente, separándola del resto de la declaración de voluntad del Estado al ratificar el tratado y considerando que el tratado en su conjunto, incluidas las disposiciones materia de la reserva inválida, continúa en vigor para el Estado en cuestión. Por otro lado, varios Estados, si no la mayoría, conjuntamente con la CDI, consideran que compete al Estado que ha formulado la reserva, al menos, participar en la decisión sobre las consecuencias que se derivan de una reserva declarada inválida. ${ }^{30}$

La posición de la "separabilidad" —en el sentido de que pretende separar la reserva del resto de la declaración de voluntad del Estado ratificante- tiene algunos serios inconvenientes de orden tanto teórico como práctico. En primer lugar, con el objetivo de mantener a los Estados dentro del sistema convencional, de tal manera que el objeto y fin del tratado se realice de forma efectiva, el órgano supervisor asume la tarea de interpretar la intención del Estado parte que ha formulado la reserva declarada inválida. Esta interpretación lleva al órgano supervisor a asumir o presumir que la reserva en cuestión no fue formulada como una condición esencial para la ratificación del tratado por el Estado parte. ${ }^{31}$ Así, se con-

30 Ver el informe de los debates en el seno de la CDI, op. cit., nota 25, y Preliminary conclusions, op. cit., nota 14, párrafo 10.

31 Ver Hampson, Françoise, Working paper, cit., nota 27, p. 30; también Pellet, Allan, Segundo Informe, cit., nota 4, p. 226. 
cluye que la intención del Estado parte es de permanecer en el tratado a pesar de que su reserva es declarada inválida y anulada. La consecuencia de este razonamiento es que el Estado en cuestión permanece obligado por la integridad del tratado sin el beneficio de la reserva. ${ }^{32}$ Ahora bien, esta posición se distancia de la fórmula de las Convenciones de Viena, pone en cuestión algunos elementos fundamentales del derecho internacional y es, al menos en ciertos casos, manifiestamente contraria a la evidencia sobre las intenciones de los Estados.

Se debe notar que varias reservas habrían sido explícitamente formuladas como un elemento esencial para que los Estados acepten el conjunto del tratado. Algunos de los ejemplos más claros serían los casos de los Estados Unidos, cuyas reservas han sido dictadas por su propio congreso, y de Trinidad y Tobago en el caso que comentamos. Que un país denuncie primero a un tratado y se readhiera inmediatamente después, esta vez formulando una reserva, constituiría una clara evidencia de que la reserva en cuestión es un elemento esencial en la adhesión al tratado. ${ }^{33}$ Los miembros del Comité que emitieron una opinión disidente en el caso Kennedy son de la opinión de que en este tipo de casos la presunción de la "separabilidad" establecida por el Comité en su Observación General 24 no sería aplicable si resulta evidente que la disposición del Estado que formula la reserva a adherirse al tratado depende de que se acepte la reserva. $^{34}$

Ignorar la reserva considerada incompatible con el objeto y propósito del tratado para considerar que el Estado parte en cuestión está obligado por las normas del tratado que explícitamente reservó, equivaldría a decir llanamente que este Estado debe asumir ciertas obligaciones sin o presumiendo su consentimiento para ello. Es este cuestionamiento al principio del consentimiento, que los Estados consideran a la base de su soberanía, el que ha sido más criticado. ${ }^{35}$

32 Observación General 24, op. cit., nota 10, p. 18.

33 Voto particular disidente caso Kennedy, cit. nota 2, párrafos 16 y 17. Para los miembros del Comité disidentes de la opinión mayoritaria "En estas circunstancias particulares, resulta evidente que Trinidad y Tobago no estaba dispuesta a ser Parte del Protocolo Facultativo sin la reserva específica, y que su re-adhesión dependía de que se aceptara esa reserva". La noticia, aun sin confirmar, de que Trinidad y Tobago ha denunciado el Primer Protocolo Facultativo del Pacto en julio del 2000, parecería sostener esta posición y confirmar nuestra perspectiva.

34 Ibidem, p. 16.

35 Ver los comentarios sobre la Observación General 24 dirigidos al Comité por los gobiernos del Reino Unido, Francia y Estados Unidos, op. cit., nota 10, ver también el Segundo Informe de Allan Pellet, cit., nota 4, pp. 226-229. El profesor Pellet concluye: "cualquiera sea su objeto, el tratado 
Sin embargo, y sin perjuicio de los argumentos críticos a la teoría de la separabilidad, en nuestra opinión sería difícil sostener que los órganos supervisores no deben llevar a cabo ningún ejercicio interpretativo sobre la intención de los Estados al ratificar el tratado. Una vez que hemos asumido que estos órganos son competentes para evaluar la validez de las reservas dentro del cuadro del ejercicio de su mandato supervisor (para examinar informes de los Estados o para recibir y examinar comunicaciones de casos individuales), no sería del todo lógico pedirles que luego de declarar una determinada reserva como inválida dejen a la discreción del Estado reservante la decisión sobre qué hacer con dicha reserva. Ciertamente, esto podría ser posible en el marco del examen de informes generales por parte de los Estados; por ejemplo, los informes que se presentan según el artículo 40 del Pacto, pero no sería tan congruente en el caso de comunicaciones individuales bajo el artículo 41 y los términos del Primer Protocolo. Tomando como ejemplo el caso Kennedy, si el Comité en lugar de proceder como hizo en relación con la reserva de Trinidad y Tobago hubiese dejado a ese país la decisión final sobre qué hacer con su reserva inválida, ese tipo de decisión hubiese irremediablemente perjudicado la competencia del Comité en el caso concreto. Parece evidente que el ejercicio de su autoridad cuasijurisdiccional impone al Comité la necesidad de tomar una decisión inmediata sobre la consecuencia jurídica de la declaración de invalidez de una reserva. ${ }^{36}$ Lo contrario equivaldría simplemente a otorgarle a la reserva la fuerza que se le negó al declararla inválida.

La fórmula de la separabilidad de las reservas inválidas presenta algunas dificultades adicionales. Parece que la regla establecida por los órganos supervisores y/o jurisdiccionales nos llevaría al establecimiento de dos sistemas de derechos y obligaciones con consecuencias jurídicas diferentes. Una entre los Estados parte en sus relaciones inter se, y, la otra, entre el órgano supervisor y los Estados parte. Parece obvio que las relaciones entre el órgano de supervisión y los Estados parte serán gobernadas por las normas establecidas por el órgano supervisor, no así las relaciones entre las partes entre sí. Sería posible, en concreto, que una misma reserva declarada y separada como inválida por el órgano supervisor sea,

36 Caso Kennedy, cit., nota 20. 
al mismo tiempo, considerada por otros Estados parte como válida y operativa en sus relaciones con el Estado que formuló la reserva. Esto llevaría naturalmente a importantes diferencias en cuanto al régimen de derechos y obligaciones. En el régimen de Viena, cuando una reserva es objetada por otro Estado la disposición materia de la reserva no entra en vigor entre los dos Estados o, si lo prefiere el Estado objetor, el conjunto del tratado no entra en vigor entre las dos. En el régimen preconizado por los órganos supervisores, cuando una reserva es declarada inválida y separada, las disposiciones materia de la reserva entran en vigor junto al resto del tratado en las relaciones entre el órgano supervisor y el Estado parte en cuestión. Esta radical diferencia en cuanto a las consecuencias jurídicas que se derivan de la declaración de invalidez de la reserva constituye el núcleo del impase sobre el que, hasta el momento, no se han encontrado soluciones satisfactorias.

Bruno Simma ha sugerido, recogiendo una fórmula de nivel regional europeo, una vía de reconciliación entre la práctica de los órganos de supervisión y el derecho de los tratados. Según esta fórmula, el Estado parte que formula una reserva asume el riesgo de si, en algún momento, sus reservas son declaradas inválidas por el órgano supervisor, la consecuencia será que la norma materia de la reserva entrará en vigor ignorándose la reserva en cuestión. ${ }^{37}$ Esta fórmula asume que el Estado reservante formula su reserva en el entendido de que el órgano supervisor puede eventualmente declararla inválida y separarla. No obstante lo atractivo de la fórmula, ella asume como dado algo que está precisamente en discusión: la competencia del órgano supervisor para separar la reserva considerada inválida e imponer a los Estados obligaciones que éstos no han querido aceptar.

La fórmula propuesta por Simma refleja, sin duda, la práctica de la Corte Europea que en el caso Loizidou consideró que Turquía, al momento de formular su reserva, no podía ignorar que la misma podía ser declarada inválida y separada dada la práctica jurisprudencial de la Corte. ${ }^{38}$ Sin embargo, es muy difícil aceptar que esta norma de nivel regional pueda ser traducida al nivel universal o a otra región sin atender a los diferentes

37 Simma, Bruno, "How distinctive are treaties representing collective interests? The case of human rights treaties", Multilateral Treaty-Making: The current status of challenges to and reforms needed in the international legislative process, Gowlland, Vera (ed.), Martinus Nijhoff Publ., The Hague, Boston, London (en imprenta), pp. 69-73.

38 Caso Loizidou, cit., nota 8. 
contextos sociopolíticos de cada una. En cualquier caso, sería muy difícil eliminar la impresión de un cambio de reglas en el camino. Muchos Estados han asumido obligaciones internacionales en virtud de tratados en el entendido de que las reservas formuladas no serían sujetas a revisión sino siguiendo las disposiciones de la Convención de Viena. La práctica de separar las reservas inválidas es manifiestamente nueva y puede considerarse una regla internacional en formación.

Sea cual fuere la fórmula, ésta tendrá implicancias prácticas, tan o más importantes que las jurídicas, a nivel de la promoción y protección de los derechos humanos. Hasta hoy se ha considerado que la adhesión más amplia y universal es una condición necesaria para lograr el propio objeto y propósito de un tratado de derechos humanos. El propio régimen de Viena en materia de reservas ha sido construido en atención a este criterio. Parece evidente que esa tendencia a la universalidad se verá mellada si los Estados entienden que la flexibilidad del régimen de reservas, la cual facilitaba las ratificaciones, ya no existe más.

Por otro lado, no debería desatenderse las preocupaciones de los órganos de supervisión. Éstos parecen querer ir más allá de una simple universalidad por la cual los tratados son ratificados de manera amplia, pero con reservas tan sustanciales que ponen en peligro el propio objeto y fin del tratado. La protección de los derechos humanos, además de universal, tiene que ser efectiva. Este criterio de efectividad ha ido adquiriendo fuerza, en un contexto en que la comunidad internacional, al menos en lo que respecta a los derechos humanos, adquiere mayor consistencia y dispone de mejores mecanismos de actuación colectiva que antes. En muy pocos otros casos como en los derechos humanos y el derecho humanitario, la necesidad de asegurar la implementación de las obligaciones de los Estados es tan aguda. Es esta necesidad la que se ha manifestado en la práctica reciente de los órganos de supervisión de los tratados de derechos humanos.

\section{DENUNCIA DE LOS TRATADOS DE DERECHOS HUMANOS}

El principio del consentimiento expresa la idea de que los Estados asumen derechos y obligaciones internacionales a través de la expresión libre y soberana de su voluntad. Este principio es la piedra angular del derecho internacional de naturaleza convencional. En principio, un Estado es totalmente libre de entrar en cualquier tipo de tratado, siempre que 
éste no contravenga una norma imperativa, a través de la expresión de su consentimiento para ello. Por ello mismo, las obligaciones de tipo convencional pueden también ser denunciadas. Sin embargo, la libertad de un Estado para denunciar tratados que ha concluido válidamente está sujeta a ciertas limitaciones en vista de los derechos de las otras partes contratantes y la estabilidad del sistema jurídico internacional. Si bien la libertad para entrar en obligaciones convencionales puede presumirse, la libertad para denunciarlas no puede serlo.

Las Convenciones de Viena de 1969 y 1986 han establecido normas básicas que regulan la denuncia de tratados. Se trata aquí, como en el resto del régimen de tratados, de reglas suplementarias a la voluntad de las partes y suficientemente flexibles para adaptarse a los distintos tipos de práctica convencional en las relaciones internacionales. Sin embargo, al igual que en el caso de las reservas, la práctica de ciertos órganos de supervisión de tratados de derechos humanos ha puesto también en cuestión el régimen de Viena en materia de denunciación de tratados de derechos humanos.

No sólo el derecho de los Estados a denunciar tratados de derechos humanos ha sido puesto en cuestión, sino también el mismo derecho en relación con cláusulas facultativas de aceptación de la competencia de ciertos órganos jurisdiccionales establecidos en virtud de tratados de derechos humanos. Evidentemente, no se trata de instituciones jurídicas similares. En el primer caso se trata de la conclusión y denuncia de un tratado, mientras que en el segundo se trata más bien de la aceptación y retiro de una declaración de aceptación de jurisdicción. No obstante, en ambos casos se trata de la expresión del consentimiento necesario tanto para aceptar obligaciones internacionales como para denunciarlas. La doctrina y la práctica internacionales han tratado, por otro lado, ambos casos de manera análoga y, por lo mismo, han aplicado un mismo conjunto de reglas a ambos.

\section{El régimen general sobre denuncia de tratados}

El régimen sobre denuncia de tratados está establecido en los artículos 55 y 56 de la Convención de Viena sobre el Derecho de los Tratados de 1969. Este mismo conjunto de normas ha sido aplicado a los retiros de declaraciones de aceptación de competencia, como se verá más tarde. El artículo 55 establece la regla general acorde con el principio del consenti- 
miento: un tratado puede denunciarse de la manera prevista en el propio tratado por las partes contratantes. Cuando un tratado contiene una disposición relativa a su propia denuncia, cualquier intento en ese sentido deberá ceñirse a lo previsto por las partes contratantes en esa cláusula. Los problemas se presentan cuando el tratado no contiene ninguna disposición referida a su propia denuncia. La cuestión en este caso es si puede válidamente presumirse la existencia de un derecho implícito a denunciar un tratado cuando ello no ha sido previsto en el mismo. ${ }^{39} \mathrm{El}$ artículo 56 de la Convención de Viena establece una fórmula que puede dar lugar a diversas interpretaciones: un tratado que no contenga disposiciones sobre su terminación ni prevea la denuncia o el retiro del mismo no podrá ser objeto de denuncia o de retiro a menos que: a) conste que fue la intención de las partes admitir la posibilidad de denuncia o retiro; o b) que el derecho de denuncia o de retiro pueda inferirse de la naturaleza del tratado.

Para Ernesto de la Guardia, este artículo de la Convención de Viena refleja la doctrina tradicional que no admite el derecho implícito de denuncia a los tratados, ${ }^{40}$ aunque agrega dos excepciones, la segunda de las cuales, que hace referencia a la naturaleza de los tratados, en nuestro concepto, se presta a una amplia interpretación. Adicionalmente, el párrafo 2 del mismo artículo establece que, en cualquier caso, una parte debe notificar con doce meses de anticipación su intención de denunciar el tratado. En palabras de De la Guardia, "resulta evidente que no se ha deseado facilitar la denuncia de estos importantes instrumentos de codificación" 41 poniendo como ejemplo a un conjunto de importantes tratados multilaterales que no establecen cláusulas en relación con su propia denuncia. La razón de esta opción es evidente: se ha querido dotar a las transacciones internacionales de la mayor seguridad y estabilidad posibles sin por ello sacrificar por completo el carácter consensual del tratado.

\section{La práctica de los órganos de supervisión de tratados de derechos humanos}

El 27 de agosto de 1997, el gobierno de la República Democrática de Corea (Corea del Norte) notificó al Comité de Derechos Humanos su in-

39 Guardia, Ernesto de la, Derecho de los tratados internacionales, Buenos Aires, Ed. Abaco, 1997, p. 299.

40 Ibidem, p. 300.

41 Idem. 
tención de denunciar el Pacto. El 29 de octubre, el presidente del Comité envió una carta al embajador de Corea del Norte enfatizando que el Comité es el "único órgano competente establecido por el Pacto en cuestiones relativas a los informes" presentados por los Estados. La carta adjuntaba una copia de la Observación General 26, discutida y aprobada el mismo día por el Comité. ${ }^{42}$

En su Observación General 26, el Comité expresa el "firme convencimiento de que el derecho internacional no permite que un Estado que haya ratificado del Pacto... lo denuncie ni se retire de él". ${ }^{43}$ Para llegar a esta conclusión, el Comité examina la cuestión de si el Pacto es denunciable o no utilizando "las normas del derecho internacional consuetudinario que se recogen en la Convención de Viena", las cuales hemos reseñado en párrafos anteriores. Después de constatar que el Pacto no contiene una cláusula que permita su propia denuncia, y de afirmar que, habida cuenta que otros tratados de derechos humanos sí contienen una cláusula de este tipo, dicha omisión fue intencional por parte de los redactores del Pacto que tuvieron el propósito deliberado de excluir la posibilidad de la denuncia, el Comité concluye que "es indudable que el Pacto no es un tratado que, por su naturaleza, entrañe un derecho de denuncia". ${ }^{44}$

Aunque las opiniones vertidas por el Comité en su Observación General 26 no han sido todavía objeto de críticas por parte de ningún Estado, sí han sido motivo de crítica por parte de algunos académicos. El profesor Bruno Simma, por ejemplo, ha remarcado que el argumento del Comité es insatisfactorio y que su lógica bien puede llevarnos a la conclusión contraria. Por ejemplo, señala él una cláusula que permite que las autoridades del país de acogida ingresen a instalaciones consulares de un país extranjero en caso de incendio existe en la Convención de Viena sobre Relaciones Consulares de 1963, pero no en la Convención de Viena sobre Relaciones Diplomáticas de 1961. Si hubiera que seguir el razona-

42 Observación General 26: Cuestiones relacionadas con la continuidad de las obligaciones del Pacto Internacional de Derechos Civiles y Políticos, CCPR/C/21/Rev.1/Add. 829 de octubre de 1997. Informe del Comité de Derechos Humanos sobre los trabajos de su 53ava sesión, vol. I, Actas Oficiales de la Asamblea General, Suplemento 40 (A/53/40), párrafo 413 y Anexo VII. Poco después de adoptada la Observación General 26, y ante la notificación del retiro norcoreano del Pacto, el secretario general de las Naciones Unidas en su función de depositario notificó a su vez a Corea del Norte que los retiros o denuncias al Pacto no estaban permitidos. Recientemente, Corea del Norte ha hecho saber su intención de cumplir con sus obligaciones convencionales en materia de presentación de informes periódicos al Comité.

43 Ibidem, p. 5.

44 Ibidem, p. 3. 
miento a contrario del Comité, la ausencia de esta cláusula en la Convención de Viena sobre Relaciones Diplomáticas de 1961 nos llevaría a concluir que fue la intención de las partes contratantes el negar la posibilidad de que las autoridades locales ingresen en instalaciones diplomáticas en caso de incendio. Sin embargo — anota Simma—, esto no es así, ya que la mayor parte de la doctrina permite la analogía en este caso. Si el razonamiento a contrario — concluye - no es determinante en este caso, ¿por qué habría de ser tan decisivo en el caso del Pacto? ${ }^{45}$

Adicionalmente, el profesor Simma señala que, en términos políticos, hay una contradicción entre, por un lado, el aliento de las Naciones Unidas a la adhesión universal de los Estados a los tratados de derechos humanos concluidos bajo sus auspicios, y, por el otro lado, la insistencia en que una vez dentro del sistema convencional los Estados no pueden salir de él. Esta posición rígida afectará, en opinión de Simma, la futura práctica de los Estados en materia de reservas: la cantidad y calidad de las reservas probablemente aumentarán con relación a cuantas menos posibilidades existan de denunciar el tratado.

Dejando a un lado sus apreciaciones de índole política, que parecen del todo pertinentes, es importante remarcar que el profesor Simma no hace alusión a los otros argumentos del Comité. El razonamiento del Comité no se centra sólo en la ausencia de la cláusula de denunciación para presumir una intención de los redactores a contrario. El Comité asigna también una excepcional importancia a la naturaleza del tratado como tratado de derechos humanos, enfatizando su carácter no temporal y caracterizando los derechos incluidos en el Pacto como derechos adquiridos en beneficio de los individuos que viven en un determinado territorio. Más adelante se verá que el profesor Simma se encuentra dentro del grupo de académicos que no apoyan la teoría de una supuesta naturaleza especial de los tratados de derechos humanos. Esto explicaría por qué, en el caso concreto de las denuncias, este autor no encuentra razón jurídica alguna en la posición asumida por el Comité.

Además de la práctica del Comité en materia de denuncia del Pacto, tenemos también la práctica muy reciente de un órgano regional, la Corte Interamericana de Derechos Humanos, en materia de retiros de declaraciones de aceptación de la competencia contenciosa de la Corte por un Estado parte en la Convención Americana de Derechos Humanos. 
En septiembre de 1999 la Corte Interamericana de Derechos Humanos (Corte Interamericana) adoptó una decisión considerando el retiro, por parte de Perú, del reconocimiento de su competencia contenciosa como inadmisible por no estar permitido en la propia Convención Americana de Derechos Humanos (Convención Americana), y por ser incompatible con el objeto y propósito de esta última. Estas recientes decisiones han recibido el apoyo explícito de otro órgano regional, la Corte Europea de Derechos Humanos. ${ }^{46}$

\section{El caso del Tribunal Constitucional de Perú y el estado del debate}

El 15 julio de 1999 el Ministerio de Relaciones Exteriores de Perú entregó a la secretaría de la Corte Interamericana una nota por la cual devolvía la notificación de la demanda referida al caso del Tribunal Constitucional, argumentando que la Corte ya no era competente sobre el caso. ${ }^{47}$ La nota señalaba que el 9 de julio del mismo año el gobierno de la República del Perú había depositado en la Secretaría General de la Organización de Estados Americanos el instrumento "mediante el cual declara que, de acuerdo a la Convención Americana sobre Derechos Humanos,... retira la declaración de reconocimiento de la cláusula facultativa de sometimiento a la competencia contenciosa de la Corte Interamericana de Derechos Humanos". Este instrumento declaraba que el retiro produciría "efectos inmediatos a partir de la fecha de depósito del mencionado instrumento" y se aplicaría a "todos los casos en los que el Perú no hubiese contestado la demanda incoada ante la Corte". De esta manera, el Perú pretendía impedir que la Corte Interamericana conociera un caso que le era políticamente muy delicado.

En sentencia sobre competencia en el caso del Tribunal Constitucional, el 24 de septiembre 1999 la Corte Interamericana declaró que "el pretendido retiro, con efectos inmediatos, por el Estado peruano, de la declaración de reconocimiento de la competencia contenciosa de la Corte Interamericana de Derechos Humanos, es inadmisible". ${ }^{48}$ La Corte se declaró entonces competente para conocer el caso.

46 Caso del Tribunal Constitucional (sentencia sobre competencia). Corte Interamericana de Derechos Humanos, 24 de septiembre de 1999. En la misma fecha la Corte Interamericana adoptó una decisión similar en otro caso contra Perú, el caso Baruch Ivcher. La Corte Europea de Derechos Humanos expresó, mediante carta, su respaldo a las decisiones adoptadas por la Corte Interamericana. Comunicado de Prensa CDH-CP13/99 de 2 de octubre de 1999.

47 Caso del Tribunal Constitucional, reproducido en el párrafo 23 de la sentencia.

48 Idem. 
Ésta no es la primera vez que un órgano jurisdiccional internacional se declara competente para conocer un caso rechazando los argumentos de una parte en el litigio cuestionando su competencia. Sin embargo, ésta sería la primera vez que un órgano de esta naturaleza se declara competente para conocer un caso sobre la base de una nueva regla en derecho internacional que no permitiría el retiro de la declaración de un Estado aceptando la competencia obligatoria de una corte de derechos humanos hecha incondicionalmente y por tiempo indefinido, si el tratado en cuestión no lo permite explícitamente. La Corte Interamericana utiliza aquí un razonamiento similar al del Comité de Derechos Humanos en su Observación General 26: la falta de voluntad expresa de las partes significa, $a$ contrario, que su intención es la de no permitir los retiros. Para comprender mejor la naturaleza y los alcances excepcionales de esta decisión, conviene detenerse en dos de sus elementos principales.

Luego de afirmar su competencia para decidir sobre la extensión de su propia competencia, en aplicación del ampliamente conocido principio de la "competencia de la competencia", ${ }^{49}$ la Corte Interamericana subraya la particular importancia de la cláusula facultativa de aceptación de su competencia dentro de la Convención para la operación y "eficacia del mecanismo de protección internacional" establecido en la Convención..$^{50}$ Recordando una norma del derecho general de tratados, la Corte Interamericana sostiene que un Estado parte en la Convención Americana sólo puede desvincularse de sus obligaciones observando las disposiciones del propio tratado. En la ocurrencia, la cláusula facultativa de jurisdicción de la Corte (artículo 62.1 de la Convención) no contiene una disposición expresa que permita a los Estados retirar su declaración de aceptación de la misma. Esto permite a la Corte concluir que, "en las circunstancias del presente caso, la única vía de que dispone el Estado para desvincularse del sometimiento a la competencia contenciosa de la Corte, según la Convención Americana, es la denuncia del tratado como un todo...". ${ }^{51}$

Para sostener esta fórmula, la Corte Interamericana declara que

al someterse a esa cláusula [de aceptación de competencia] queda el Estado vinculado a la integridad de la Convención... El Estado sólo puede sustraerse a la competencia de la Corte mediante la denuncia del tratado como 
un todo... El instrumento de aceptación de la competencia de la Corte debe, pues, ser apreciado siempre a la luz del objeto y propósito de la Convención Americana como tratado de derechos humanos. ${ }^{52}$

La Corte Interamericana señala además que la Convención fue clara al prever la denuncia de "esta Convención" y no la denuncia o el retiro de partes o cláusulas de la misma, lo cual afectaría su integridad. No parece haber sido la intención de las Partes tal cosa ni tampoco se puede inferir de la naturaleza de la Convención como tratado de derechos humanos. ${ }^{53}$

Conviene observar, en primer lugar, que, para concluir que el retiro de una declaración de aceptación de la competencia de la Corte Interamericana por tiempo indefinido es inválido, la Corte considera que dicho retiro es una denuncia parcial del tratado principal. ${ }^{54}$ Esta operación, que a primera vista parece simple, tendrá, sin embargo, importantes consecuencias al momento de decidir el conjunto de reglas aplicables al caso. En la ocurrencia, la Corte considera que el derecho de tratados es el aplicable, concretamente el artículo 44 de la Convención de Viena de 1969. Ahora bien, tanto la aplicación de las reglas del derecho de tratados a la operación de la cláusula facultativa como el tratamiento del retiro del reconocimiento de esta cláusula como un caso de denuncia parcial presentan importantes y serios problemas de orden doctrinal y práctico.

La Corte Interamericana no establece una analogía, sino que simplemente trata a las obligaciones originadas en virtud de la operación de la cláusula facultativa como obligaciones originadas en la Convención misma, y por tanto denunciables sólo según lo establecido en el propio tratado. La Corte pasa por alto la naturaleza jurídica de la cláusula facultativa y la manera como los Estados adquieren obligaciones según esta última. La fórmula adoptada por la Corte supondría que la aceptación incondicional e indefinida de su competencia es, en la práctica, equivalente a una adhesión parcial y diferida de la propia Convención. De esa manera, la aceptación incondicional de la competencia de la Corte no sería sino un acto diferido del principal acto jurídico: la adhesión a la Convención.

52 Ibidem, p. 45.

53 Ibidem, p. 50.

54 En ciertos tratados de derechos humanos, como las convenciones Americana y Europea, la competencia del órgano jurisdiccional, la Corte Interamericana y Europea, respectivamente, depende de una cláusula que es parte del tratado principal, mientras que en el Pacto Internacional de Derechos Civiles y Políticos, la competencia del órgano cuasijurisdiccional, el Comité, depende de un instrumento distinto y separado como el Protocolo Facultativo. 
Ahora bien, así como la denuncia parcial está permitida en el derecho de tratados sólo si las partes así lo disponen, la adhesión parcial también debe estar explícitamente permitida en el tratado. ${ }^{55}$ La Convención Americana no contiene ninguna disposición que permita la ratificación o adhesión parcial a ella. De hecho la adhesión parcial a un tratado internacional no ha sido frecuente como institución jurídica debido a la existencia de la institución de la reserva. ${ }^{56}$ Mediante la reserva un Estado se puede adherir al conjunto de un tratado excluyendo o modificando los efectos jurídicos de algunas de sus cláusulas. Aceptar que el retiro de una aceptación incondicional de una cláusula facultativa de jurisdicción es equivalente a una denuncia parcial equivaldría, a su vez, a aceptar que una figura tal como la adhesión parcial está permitida por la Convención Americana, lo cual, en la evidencia, no es cierto.

En el razonamiento de la Corte Interamericana, la cláusula facultativa de aceptación de jurisdicción (artículo 62.1 de la Convención Americana) no tiene carácter de mecanismo diferenciado de la Convención misma, y pasa a ser una cláusula convencional más que opera, y puede ser denunciada, con el tratado principal en su conjunto. La naturaleza jurídica de la cláusula facultativa de aceptación de jurisdicción, dada por su carácter de mecanismo que opera con base en actos jurídicos distintos e independientes del acto jurídico por el cual se acepta la Convención misma, se pierde en lo esencial. En pocas palabras: la cláusula facultativa de la Convención Americana deja de ser tal, aunque, curiosamente, sólo para efectos del régimen jurídico aplicable a los retiros de declaraciones de aceptación por tiempo indefinido.

La doctrina más autorizada reconoce que el sistema de la cláusula facultativa de la Corte Internacional de Justicia (CIJ) es un mecanismo sui generis que opera sobre una base convencional y unilateral a la vez y que por tanto origina un régimen jurídico especial que no es el del derecho de los tratados, sino un régimen especial para estos sistemas. ${ }^{57}$ Rosenne enu-

55 El artículo 17.1 de la Convención de Viena sobre el Derecho de los Tratados dispone que "el consentimiento de un Estado en obligarse respecto de parte de un tratado solo surtirá efecto si el tratado lo permite o los demás Estados contratantes convienen en ello".

56 Ver Spiliopoulou, Sia, "Reservation clauses in treaties concluded within the Council of Europe", International and Comparative Law Quarterly, vol. 48, julio de 1999, pp. 479-514, que señala que la figura de la adhesión parcial es posible y se usa en el contexto del Consejo de Europa.

57 Rosenne, Shabtai, The Law and Practice of the International Court, 1920-1996, vol. II. Jurisdiction. The Hague, London, Boston, Martinus Nijhoff Publ., 1997, pp. 823-831; Szafarz, Renata, The Compulsory Jurisdiction of the International Court of Justice, Dordrecht, Boston, London, Martinus Nijhoff Publ., 1993, pp. 79-82. 
mera un conjunto de elementos que distinguen al sistema de la cláusula facultativa de un tratado cualquiera, incluyendo el significado distinto asignado a las reservas y, sobre todo, el hecho de que las declaraciones de aceptación de la cláusula pueden ser modificadas o terminadas unilateralmente, lo cual no ocurre en ningún sistema convencional. ${ }^{58}$ Por su parte, Szafarz, después de hacer un recorrido por la jurisprudencia de la Corte Internacional de Justicia y la opinión de varios autores, incluyendo las opiniones disidentes e individuales de varios jueces en el caso Nicaragua, arriba a la misma conclusión: la cláusula facultativa de jurisdicción es una estructura jurídica sui generis que consiste en elementos contractuales y unilaterales y origina una red de relaciones bilaterales paralelas. ${ }^{59}$

Ahora bien, la cláusula facultativa del artículo 62.1 de la Convención Americana ha sido elaborada bajo la misma idea y siguiendo el modelo de su similar en la Convención Europea, la cual, a su turno, tomó como modelo el artículo 36.2 del Estatuto de la Corte Internacional de Justicia. ${ }^{60}$ Es evidente que la cláusula facultativa de la Convención Americana fue concebida en los mismos términos que aquella de la CIJ y, en ese sentido, las reglas que gobiernan la operación de una serían aplicables, mutatis mutandis, a la otra.

En ese sentido, la Corte Internacional de Justicia ha establecido una regla sobre retiros de declaraciones de aceptación de jurisdicción por tiempo indefinido. En el caso Nicaragua, esta Corte discutió la cuestión del derecho implícito de retirar las declaraciones hechas por un tiempo indefinido y, por extensión, el régimen legal aplicable en la materia. La conclusión de la CIJ, aplicando por analogía la norma del artículo 56.2 de la Convención de Viena sobre Derecho de los Tratados, que exige un periodo mínimo de preaviso de un año para las denuncias de tratados que no contienen una cláusula al respecto, fue que cualquier retiro de este tipo requeriría el mismo plazo razonable de preaviso. ${ }^{61}$ La aplicación de este

58 Ibidem, p. 825.

59 Szafarz, Renata, op. cit., nota 57, p. 81.

60 Observations of the Inter-American Commission on Human Rights concerning the return of the application in the case of the constitutional court v. Peru (11.760), and the jurisdiction of the Inter-American Court of Human Rights. Disponible en internet: www.cidh.org. La Comisión cita los travaux preparatoires de la Convención Europea y hace alusión a los trabajos preparatorios de la propia Convención Americana.

61 Case concerning Military and Paramilitary Activities in and Against Nicaragua (jurisdiction), ICJ Reports 1984, párrafo 63. Notemos, sin embargo, que si bien la Corte Internacional aplica el derecho de tratados no lo hace más que por analogía y atendiendo más al principio de la buena fe que a una intención de asimilar el sistema de la cláusula facultativa a un sistema convencional cualquiera. 
razonamiento y de la norma establecida por la CIJ hubiese bastado a la Corte Interamericana para asegurar su competencia en el caso concreto.

Además de los problemas teóricos, la aplicación práctica de la fórmula establecida por la Corte Interamericana parece también problemática. La estructura del razonamiento de la Corte no se aplicaría al conjunto del sistema de la cláusula facultativa, ya que sólo sería aplicable a las declaraciones de aceptación incondicionales y por tiempo indefinido. Una declaración condicionada o por tiempo definido contiene en sí misma la autorización para su retiro; por tanto, jamás podría ser asimilada a una denuncia parcial del tratado. Así, estaríamos ante un curioso panorama en el que un Estado que acepta la competencia de la Corte Interamericana de manera más limitada, por ejemplo, reservando su derecho a retirar su declaración en cualquier momento, gozaría de más derechos que aquel que lo hace de manera indefinida e incondicional. Se estaría, de esta manera, alentando a los Estados a formular aceptaciones de competencia limitadas y con la mayor cantidad de condiciones posibles. Es por lo menos cuestionable que ésta sea la mejor manera de promover el papel de la Corte en la protección de los derechos humanos en la región.

Adicionalmente, al establecer que un Estado sólo puede deshacerse de sus obligaciones bajo la cláusula facultativa denunciando la Convención misma podría obtenerse un efecto no deseado, y más perjudicial, la denuncia de la Convención como tal. No deja de parecer chocante el hecho de que los Estados tengan el derecho de denunciar el tratado principal, la fuente principal de las obligaciones, y no una cláusula de jurisdicción cuyo objetivo es establecer un mecanismo de evaluación de la aplicación de las obligaciones del tratado principal. Aparentemente la máxima "el que puede lo más puede lo menos" (si se puede denunciar la fuente de las obligaciones también se puede denunciar el mecanismo de evaluación) no se aplicaría aquí, y las razones para ello quedan en el misterio. Finalmente, no está del todo claro por qué un argumento a contrario, en el sentido de que la falta de cláusula de salida implica la intención de no permitir retiros, funcionaría aquí, especialmente si tenemos en cuenta que existe una regla al respecto: la regla establecida por la Corte Internacional de Justicia que presume que el derecho del retiro existe aunque no de manera discrecional.

El segundo elemento a remarcar en la decisión se refiere a la diferencia que la Corte Interamericana entiende que existe entre su propia juris- 
dicción y la de la CIJ. En su razonamiento, la Corte Interamericana descarta "cualquier analogía" entre

por un lado, la práctica estatal permisiva desarrollada bajo el artículo 36.2 del Estatuto de la Corte Internacional de Justicia, y, por otro lado, la aceptación de la cláusula facultativa de la jurisdicción obligatoria de esta Corte, teniendo presentes el carácter especial, así como el objeto y propósito de la Convención Americana...

En efecto, la solución internacional de casos de derechos humanos (confiada a tribunales como las Cortes Interamericana y Europea de Derechos Humanos), no admite analogías con la solución pacífica de controversias internacionales en el contencioso puramente interestatal (confiada a un tribunal como la Corte Internacional de Justicia); por tratarse, como es ampliamente reconocido, de contextos fundamentalmente distintos, los Estados no pueden pretender contar, en el primero de los contextos, con la misma discrecionalidad con que han contado tradicionalmente en el segundo. ${ }^{62}$

A este respecto, la Corte sigue las opiniones en el mismo sentido de la Corte Europea de Derechos Humanos en el caso Loizidou. En este caso, la Corte Europea señaló, entre los elementos que marcan la diferencia entre ambas jurisdicciones, el hecho de que la Corte Internacional de Justicia es un tribunal autónomo sin vínculos con un tratado normativo como la Convención Europea. Además, los conflictos que la Corte Internacional resuelve pueden involucrar cualquier dominio del derecho internacional..$^{63}$

Para la Corte Interamericana, tanto como para la Europea, la diferencia fundamental en relación con el papel y objetivos de los respectivos tribunales constituye una razón de peso para alejarse de la práctica de la Corte Internacional. Sin embargo, fuerza hay de señalarlo, mientras la Corte Europea utiliza el argumento para decidir que las restricciones formuladas por Turquía a su declaración de aceptación de jurisdicción no eran válidas, la Corte Interamericana lo utiliza en el contexto de una decisión aún más radical que considera inválido el retiro de tal tipo de declaraciones de aceptación de jurisdicción.

Si bien es cierto que las diferencias entre los tipos de jurisdicción son importantes, éstas no son cruciales. En todo caso, ellas no llevan a la conclusión a la que arriba la Corte Interamericana. No olvidemos que la Convención Americana otorga a esta última y a la Comisión Interamericana 
de Derechos Humanos (la Comisión) jurisdicción en casos de disputas interestatales (artículos 45.1 y 62.3 de la Convención), y que la Corte Internacional de Justicia es designada como órgano jurisdiccional competente en un buen número de tratados de derechos humanos a nivel universal.

Sea como fuere, y sin perjuicio de la pretendida naturaleza jurídica sui generis o diferente de las cláusulas de jurisdicción en los sistemas convencionales de protección de los derechos humanos, la cuestión de por qué no es posible en esos sistemas, a diferencia de la práctica frente a la Corte Internacional, el retiro de una aceptación incondicional, sigue siendo vigente. Al respecto, la Corte Interamericana ha brindado un único argumento razonable para considerar que un Estado, al aceptar incondicionalmente la competencia de la Corte, ha asumido una obligación permanente e indenunciable. Este argumento sería la suprema necesidad de asegurar la efectiva protección de los derechos humanos en la región. ${ }^{64}$ Esta tarea especial y de suprema importancia habría sido confiada a los mecanismos del sistema interamericano de derechos humanos, la Corte y la Comisión, y en opinión de la Corte serían suficientes para imponer a un Estado la jurisdicción internacional aun contra la manifiesta voluntad en contrario de aquél.

Antes de finalizar esta sección, es importante hacer una última observación sobre el carácter de la decisión de la Corte Interamericana en el caso Tribunal Constitucional.

Aunque, como parece natural, la decisión de la Corte Interamericana en el caso del Tribunal Constitucional tiene carácter vinculante sólo para el caso concreto, la naturaleza y circunstancias de la decisión, incluido el apoyo de la Corte Europea, establecen una regla de alcance general que indudablemente será aplicada en el futuro para casos similares. La Corte Interamericana ha optado por una regla estricta que implica la virtual denegación de un presunto derecho a retirar declaraciones de aceptación de competencia hechas por tiempo indefinido y sin condiciones. Sin embargo, tal tipo de decisión no era la única que se presentaba como posible para los jueces de la Corte. De hecho, el documento con las observaciones de la Comisión Interamericana de Derechos Humanos remitida a la Corte Interamericana $^{65}$ nos presenta una variedad de alternativas que la Corte Interamericana descartó explícitamente al preferir la fórmula adoptada. 
En efecto, la Comisión analiza tres soluciones para el caso, todas ellas favorables a preservar la competencia de la Corte frente al pretendido retiro peruano, aunque la posición final de la Comisión será la misma que aquella que la Corte asumirá posteriormente. Primero, la Comisión sostiene que el retiro peruano, aun si se considerara válido, no impide que la Corte asuma competencia en el caso en cuestión, el del Tribunal Constitucional peruano, ya que la jurisdicción de la Corte ha sido puesta en acción con la introducción de la demanda por parte de la Comisión, y en ese momento la declaración peruana estaba vigente y era válida. Un acto unilateral de un Estado cualquiera no puede privar a la Corte de su competencia una vez que ésta ha sido puesta en marcha. El argumento nos parece impecable y enteramente fundado en la jurisprudencia relevante de la Corte Internacional de Justicia. Sólo este primer argumento hubiera bastado para afirmar la competencia de la Corte Interamericana en el caso concreto. Sin embargo, la Comisión prosigue con un segundo argumento. La Comisión sostiene que, aun si se considerara válido el retiro peruano, éste no tendría, en ningún caso, efecto inmediato, como lo pretendía el Perú. Esta segunda fórmula recoge la jurisprudencia de la CIJ en el caso Nicaragua, en el cual esta Corte estableció que doce meses eran un periodo de preaviso razonable para el retiro de declaraciones de reconocimiento de competencia por tiempo indefinido. Ahora bien, ninguno de estos dos argumentos es retenido por la Comisión que prefiere, como la Corte, una solución de alcance más general y radical. Al parecer, la Corte estuvo, esta vez, más preocupada en establecer una regla general sobre la materia que en asegurar su propia jurisdicción en el caso concreto.

\section{LOS TRATADOS DE DERECHOS HUMANOS COMO TRATADOS DE NATURALEZA ESPECIAL}

Al establecer reglas diferentes a las de la comúnmente aceptada práctica internacional, los órganos supervisores y/o jurisdiccionales de derechos humanos han, de manera invariable, hecho alusión a la naturaleza especial de dichos tratados como el fundamento y justificación de sus decisiones.

Además de los campos del derecho internacional tratados en las secciones anteriores, este razonamiento se ha aplicado también al campo de la sucesión de Estados en materia de tratados de derechos humanos. En este campo, la práctica de ciertos órganos de Naciones Unidas encargados 
de la promoción y supervisión de los derechos humanos ha sido clara en aplicar una norma de sucesión automática. ${ }^{66} \mathrm{~A}$ este respecto, la práctica de ciertos Estados parecería sugerir la existencia de una norma de sucesión automática como parte del derecho consuetudinario, aunque algunos autores opinan que tal práctica como base de una norma emergente es aun ambigua, sin perjuicio de que en el futuro pueda llegar a desarrollarse. ${ }^{67}$

Un razonamiento similar se ha desarrollado en el ámbito de las reglas de interpretación aplicables a los tratados de derechos humanos. Los órganos jurisdiccionales de derechos humanos, en especial, han subrayado la necesidad de interpretar las cláusulas de los tratados de derechos humanos de tal manera que se resguarde la operación del tratado y la efectiva protección que aquél brinda. Para ello se debe dar a los términos del tratado el significado comúnmente aceptado en el presente, y no en el momento en que se redactó el tratado. Mediante dicha regla de interpretación, las cláusulas del tratado estarían en permanente evolución, y el tratado sería un documento vivo. ${ }^{68}$

Cuando se habla de la especificidad de los tratados de derechos humanos, o de la naturaleza especial del régimen de derecho internacional aplicables a ellos, se hace alusión, con variada frecuencia, a un conjunto de elementos. Se menciona, especialmente, que estos tratados presentarían una estructura de derechos y obligaciones para los Estados parte diferente al de otros tratados de tipo "clásico". Los tratados de derechos humanos no tendrían como objeto el establecer una relación equilibrada entre los derechos y obligaciones que las partes se reconocen mutuamente, y en ese sentido no estarían basados en la reciprocidad, ni su implementación puede llevarse a cabo de manera bilateral. Esta posición doctrinal se basa en varias manifestaciones jurisprudenciales en ese sentido.

Así, en su opinión consultiva sobre reservas a la Convención contra el Genocidio en 1951 la Corte Internacional de Justicia declaró, refiriéndose a dicha Convención:

En una convención de esa índole, los Estados contratantes no tienen intereses propios; sólo tienen, todos y cada uno, un interés común, el de preser-

66 Poupart, Isabelle, "Succession aux traités et droits de l'homme: vers la reconnaissance d'une protection ininterrompue des individus", en Eisemann, Pierre M. y Koskenniemi, Martti (eds.), $L a$ succession d'Etats: la codification à l'épreuve des faits, The Hague, Boston, London, 2000. Académie de Droit International de la Haye, Martinus Nijhoff Publ.

67 Simma, Bruno, op. cit., nota 4, p. 357.

68 Idem, ver también caso Loizidou, cit., nota 8, p. 71. 
var los fines superiores que son la razón de ser de la convención. De ello se desprende que, respecto de una convención de esta índole, no se puede hablar de ventajas o desventajas individuales de los Estados, ni tampoco de un perfecto equilibrio contractual que se ha de mantener entre derechos y obligaciones. ${ }^{69}$

Esta opinión fue, diez años después, retomada y desarrollada por la Comisión Europea de Derechos Humanos que, en el caso Pfunders (Austria contra Italia), sostuvo que el propósito de la Convención Europea no era el establecimiento de derechos y obligaciones mutuas para los Estados parte, sino el establecimiento de un "orden público común" de las democracias libres de Europa. La Comisión Europea continuó diciendo que "las obligaciones asumidas por las Altas Partes Contratantes en la Convención son esencialmente de un carácter objetivo, diseñadas para proteger los derechos fundamentales" de los individuos. ${ }^{70}$

La Corte Interamericana de Derechos Humanos ha seguido la misma línea de pensamiento en su Opinión Consultiva de 1982 sobre los Efectos de las Reservas sobre la Convención Americana. ${ }^{71}$ Las mismas consideraciones han inspirado varias otras decisiones de órganos de supervisión de tratados de derechos humanos, algunas de las cuales se han reseñado más arriba en este trabajo.

Sin embargo, las afirmaciones anteriores deben ser tomadas con cautela. Diversos autores han observado una serie de inconvenientes a la fórmula que postula la especial naturaleza de los tratados de derechos humanos. Así, en primer lugar, no parece posible definir cuáles son los tratados de derechos humanos, ya que muchos tratados que aparentemente no son relativos a los derechos humanos contienen, no obstante, disposiciones importantes que les atañen de manera directa o indirecta. Aun si fuera posible establecer un catálogo de tratados de derechos humanos a los cuales atribuir un carácter especial, nos encontramos con el obstáculo insuperable que dentro de cada uno de ellos se puede encontrar tanto cláusulas contractuales como cláusulas normativas. Sería materialmente imposible, pues, adjudicar un supuesto carácter objetivo al tratado en su conjunto cuando varias de sus cláusulas son manifiestamente de carácter contractual bilateral. Finalmente, aunque es cierto que las disposiciones esencia-

71 Corte Interamericana, op. cit., nota 9. 
les de estos tratados gozan de un carácter "objetivo" u normativo — por oposición a contractual o recíproco - esta característica no parecer ser exclusiva de estos tratados, ya que muchos otros, especialmente aquellos relativos al medio ambiente, el desarme, y los espacios comunes, presentan características similares: crean un orden normativo o un código de conducta que los Estados parte se obligan a respetar.

En segundo lugar hay que enfatizar que el elemento de reciprocidad, si bien no es el determinante en la estructura y operación del tratado, está de todas maneras presente en un segundo plano. Esto parecería fluir de lo establecido por la Corte Europea en el caso Irlanda contra Reino Unido de 1978: "a diferencia de los tratados internacionales de tipo clásico, la Convención contiene más que compromisos recíprocos entre las partes contratantes. Ella crea, sobre y más que una red de compromisos mutuos y bilaterales, obligaciones objetivas que en palabras del preámbulo gozan de 'ejecución colectiva"'.72

Por otro lado, parte de la doctrina ha reaccionado de manera crítica hacia la idea de que los tratados de derechos humanos no originarían derechos y obligaciones recíprocos. ${ }^{73}$

Kamminga, por ejemplo, ha remarcado enérgicamente el elemento de reciprocidad en los tratados de derechos humanos basándose en la práctica internacional de escrutinio y responsabilidad mutua por parte de los Estados parte en dichos tratados. ${ }^{74}$ Otros autores, como Prevost, han subrayado la permanencia del elemento bilateral y de reciprocidad en los tratados de derechos humanos y de derecho humanitario, así como su importancia en un contexto en el que el sistema internacional mantiene todavía una estructura interestatal y se caracteriza por la ausencia de mecanismos o autoridad centralizados capaces de resguardar e implementar el ordenamiento jurídico internacional. ${ }^{75}$

72 Ireland v. United Kingdom, European Court of Human Rights, Series A N 25 (1978), p. 90.

73 Simma, Bruno, op. cit. nota 4, p. 370. Simma califica a esta doctrina como un uso "negativo" y "destructivo" del concepto "orden objetivo", y enfatiza que los tratados de derechos humanos son como cualquier otro tratado multilateral. Éstos crean derechos y obligaciones para las partes de tal modo que cada una está obligada frente a la otra a cumplir con sus obligaciones y, recíprocamente, cada parte tiene un derecho correlativo a que el tratado sea cumplido integralmente por las otras partes contratantes. Opinión similar ha sido expresada por Henkin, Louis, op. cit., nota 2.

74 Kamminga, Menno, Inter-state Accountability for Violations of Human Rights, Philadelphia, University of Pennsylvania Press, 1992.

75 Provost, René, "Reciprocity in human rights and humanitarian law", British Yearbook of International Law, 1994, pp. 383-454. 
Todos los tratados conservan, en mayor o menor medida, un elemento de reciprocidad en los derechos y obligaciones que las partes se deben la una a la otra. Puede decirse que en los tratados de derechos humanos este elemento es residual, pero sería un error negar su presencia. Kamminga ha observado lúcidamente a este respecto que si los Estados hubieran deseado comprometerse sólo unilateralmente o hacia un abstracto interés común en lugar de obligarse el uno hacia el otro por medio de un acuerdo internacional, una declaración unilateral hubiese bastado para ese propósito y no era necesario un tratado. Del hecho que han preferido concluir tratados se sigue que los Estados también quisieron asumir derechos y obligaciones frente a los demás Estados participantes. ${ }^{76}$

Sea cual fuere el lugar que los derechos y obligaciones recíprocas entre las partes ocupan dentro de un tratado de derechos humanos, su carácter consensual permanece intacto. Es importante recordar que los tratados de derechos humanos son, después de todo, tratados internacionales. ${ }^{77}$ Deben su existencia a la manifestación de voluntad consensual de los Estados parte, y tanto su estructura como su operación obedecen a este principio. La prueba definitiva de que ello es así reside en que cualquier tratado de derechos humanos puede ser modificado o terminado por los mismos Estados que la elaboraron. Es un principio reconocido del derecho internacional que los Estados sólo asumen obligaciones que han voluntariamente aceptado, aunque este principio contenga ciertas excepciones. ${ }^{78}$ Esto es aún más claro con respecto al derecho de tratados. La Convención de Viena de 1969 lo expresa tanto en su preámbulo como en su artículo 34, según el cual un tratado no crea obligaciones ni derechos para un tercer Estado sin su consentimiento.

De lo anterior se sigue que los tratados de derechos humanos no parecen presentar el carácter especial pretendido por los órganos de supervisión y parte de la doctrina. Ahora, si los tratados de derechos humanos no tienen un carácter especial en virtud de su estructura interna y su carácter normativo, ¿en qué podría consistir este presunto carácter especial? Pellet ha sugerido correctamente que dicha especificidad viene dada por el hecho de que son instrumentos que crean órganos encargados de supervisar

76 Kamminga, Menno, op. cit., nota 74, pp. 136-138.

77 Ver Pellet, Segundo Informe, cit., nota 4, pp. 95-97; Reuter, Paul, Introduction au Droit des Traites, París, Presses Universitaires de France, 1995, pp. 20-21.

78 Ver Tomuschat, Christian, "Obligations Arising for States Without or Against their Will”, Recueil des Cours de l'Académie de Droit International de La Haye, 1993-VI, vol. 241, pp. 195-374. 
su aplicación. ${ }^{79}$ Por voluntad de las partes, estos órganos tienen la atribución de supervisar el cumplimiento del tratado por las partes contratantes, y para ello deben determinar la extensión de los compromisos asumidos, interpretar el alcance de las cláusulas, evaluar la licitud de las reservas formuladas y, por supuesto, definir el alcance de su propia competencia. Cuando estos órganos han sido dotados de competencia adjudicatoria en casos individuales o interestatales, no hay virtualmente nada que diferencie su tarea de aquella de la Corte Internacional de Justicia. Así, deberán asegurarse del alcance de su competencia en el caso concreto, y para ello deben verificar el reconocimiento de su competencia por los Estados.

Todo esto no debería cuestionar, y de hecho no lo hace en la práctica, las bases fundamentales del derecho internacional en general y del derecho de tratados en particular. Sin embargo, cuando estos órganos, más allá de evaluar la licitud de las reservas formuladas, separan aquellas declaradas inválidas del conjunto de la manifestación de voluntad del Estado parte en cuestión al cual consideran obligado por el conjunto del tratado, incluyendo la cláusula materia de la reserva, parecería que estamos en una posición que es difícilmente compatible con los principios fundamentales reseñados más arriba. Igualmente, cuando estos órganos con atribuciones jurisdiccionales o cuasijurisdiccionales consideran que aquellos Estados que han reconocido incondicional e indefinidamente su competencia no pueden después retirar ese reconocimiento, estaríamos también en una posición que compromete el propio carácter consensual de la institución de la cláusula facultativa y los sistemas convencionales en su conjunto. ${ }^{80}$

El carácter consensual de las obligaciones de tipo convencional asumidas por los Estados parece estar en cuestión cuando los órganos de supervisión o jurisdiccionales de ciertos tratados de derechos humanos adoptan decisiones cuyo efecto último es la imposición sobre los Estados de obligaciones que éstos se han negado explícitamente a asumir. Sin duda la intención de estos órganos es cumplir con su papel de guardianes de un ordenamiento normativo, el conjunto de derechos fundamentales de la persona, que en sí mismo va más allá de cualquier base convencional. Sin embargo, tienen que hacerlo en un contexto y con instrumentos de este derecho de orden convencional que quizá no son los más apropiados para su tarea y que responden a los parámetros del derecho internacional interestatal. 
Los argumentos esgrimidos para adoptar este curso de acción no ofrecen razones jurídicas convincentes dentro del paradigma consensualista del derecho internacional. La conveniencia de mantener a los Estados, aun contra su voluntad, dentro de tal o cual sistema convencional de protección de los derechos humanos de tal manera que se logre la realización del objetivo último de estas convenciones, la efectiva protección de los individuos, no parece ser un argumento jurídico válido dentro de un sistema que reposa sobre el consentimiento de los Estados para la realización de cualquier objetivo convencional.

La imposición de obligaciones internacionales sobre los Estados sin su consentimiento, o presumiendo su existencia, implicaría sin duda una suerte de legislación o constitución internacional, la cual parece estar todavía en el dominio de la teoría o los deseos, a pesar de los avances interesantes en tiempos recientes.

En este sentido, podría decirse que la práctica de los órganos de supervisión de tratados de derechos humanos se enmarca en el proceso de transformación del derecho internacional y la creación de estructuras más apropiadas para la implementación y resguardo de conceptos tales como obligaciones erga omnes o normas de jus cogens.

En cuanto al contenido de las normas de derecho internacional que se proponen, resta una sola observación. Como quiera que ciertos órganos de supervisión de tratados de derechos humanos han establecido que las normas de derecho internacional originadas en la práctica jurisdiccional de la Corte Internacional de Justicia no son aplicables ni siquiera por analogía, estos mismos órganos han establecido nuevas normas que por su novedad, y por estar insertas en una estructura general todavía marcada por el bilateralismo y consensualismo, no están todavía bien definidas y se prestan a razonamientos inconsistentes. Sin embargo, la no aplicación de ciertas normas establecidas en la práctica de los Estados y la CIJ, así como su reemplazo por otras, no significa, y no debe significar, un rechazo total a las normas y práctica general. A este respecto, sería mucho más provechoso ver en las normas generales una suerte de reglas complementarias o supletorias que subyacen y/o pueden ceder frente a reglas específicas en un campo determinado. ${ }^{81}$

81 Debe notarse que el papel de la jurisprudencia de la CIJ ha sido y es fundamental en el desarrollo de la doctrina de los derechos humanos. Ciertamente, la CIJ no opera, como la Corte Interamericana y la Europea, en el marco de un solo tratado de derechos humanos, y en ese sentido no es una corte de derechos humanos. No obstante, la Corte Internacional de Justicia tiene jurisdicción para 
La existencia y operación de estos órganos expresan, en cierta manera, una paradoja en la comprensión consensualista del derecho internacional. Por un lado, estos órganos han sido establecidos en virtud de tratados que expresan el consentimiento de los Estados parte que les han confiado ciertas funciones de supervisión. Por otro lado, el ejercicio de sus funciones, por parte de estos órganos, parece implicar mucho más de lo que los Estados parte en el tratado pudieron originalmente prever. Como resultado, estos órganos asumen, cada vez más con mayor frecuencia, posiciones que parecen prescindir de su origen consensual o convencional. No es difícil ceder a la tentación de ver en la práctica de estos órganos los signos incipientes de un orden constitucional internacional basado en la absoluta primacía de ciertas normas y valores fundamentales. Resta por verse hasta dónde llegará esta tendencia, y si el genio, una vez fuera de la botella, tendrá más poder que el dueño de ella.

\section{CONCLUSIONES}

Las normas de derecho internacional reflejadas en las Convenciones de Viena de 1969 y 1986 establecen un régimen flexible y adaptable a diversos tipos de tratados. Sin embargo, ellas no dan, ni pretenden dar, respuestas para todo. El derecho internacional provee respuestas a problemas que se presentan en la práctica. Ni la Opinión Consultiva de 1951 sobre reservas a la Convención contra el Genocidio de la Corte Internacional de Justicia, ni las Convenciones de Viena intentaron dar una res-

resolver casos contenciosos en virtud de un número de tratados cuyo carácter de tratados de derechos humanos es indudable, como la Convención contra el Genocidio, o la Convención contra la discriminación racial. La importancia del papel de la CIJ en el desarrollo de la doctrina de los derechos humanos resulta evidente si recordamos que ha sido la CIJ la creadora de conceptos tales como "obligaciones erga omnes" y el de "obligaciones objetivas", los cuales constituyen hoy el fundamento de la jurisprudencia de las cortes de derechos humanos. Ver Reservations to the Convention on Genocide (Advisory Opinion), op. cit, nota 6; también Case concerning the Barcelona Traction, Light and Power, ICJ Reports 1970, p. 32; Case concerning application of the Convention on the prevention and punishment of the crime of Genocide (Bosnia and Herzegovina $v$. Yugoslavia) Preliminary Objections, ICJ Reports 1996, pp. 596 y siguientes. Respecto al aporte de la CIJ en cuanto órgano jurisdiccional en materia de derechos humanos y otros valores e intereses colectivos, ver de manera general Schwebel, Stephen, "The Treatment of Human Rights and of Aliens in the International Court of Justice", en Vaughan Lowe y Malgosia Fitzmaurice (eds.), Fifty years of the International Court of Justice. Essays in honour of Sir Robert Jennings, Cambridge University Press, 1996; Gowlland, Vera, "Judicial insights into fundamental values and interests of the International Community", en Müller, A., Raic, D., Thuranszky, J. (eds.), The International Court of Justice: its future role after 50 years, The Hague, Martinus Nijhoff, 1997. 
puesta específica al tema planteado por los tratados de derechos humanos en los cuales existen órganos de control y supervisión de naturaleza jurisdiccional o cuasijurisdiccional. El derecho internacional no ha sido establecido de manera definitiva en esos instrumentos, sino que, por el contrario, está en constante evolución.

Las decisiones del Comité de Derechos Humanos y de las Cortes Interamericana y Europea en materia de reservas y denuncias a tratados de derechos humanos o a cláusulas facultativas de reconocimiento de competencia dentro de ellos constituyen un paso fundamental en el desarrollo progresivo del derecho internacional. Sin embargo, este desarrollo implica confusión y riesgos que no pueden desatenderse desde el punto de vista político y jurídico. A lo largo de este artículo hemos tratado de mostrar que las contribuciones y pretensiones doctrinales de los órganos de supervisión de tratados de derechos humanos presentan importantes limitaciones teóricas y prácticas en el marco del derecho internacional actual.

Las normas internacionales de derechos humanos establecidas por vía convencional no son de una naturaleza tal que se puedan imponer a los Estados sin o presumiendo su consentimiento. Si bien los tratados de derechos humanos constituyen ordenamientos normativos y no solamente un conjunto de derechos y obligaciones recíprocas entre las partes en el tratado, no es del todo claro por qué a ese régimen normativo no se aplicaría el principio fundamental del derecho de tratados que requiere la aceptación de los Estados para constituir obligaciones vinculantes sobre éstos. Los sistemas convencionales de derechos humanos son tratados normativos, aceptados por los Estados a través de la expresión de su consentimiento. No parece, pues, en principio, que constituyan un régimen diferente y separado dentro del derecho internacional.

Sin perjuicio del carácter consensual de los tratados de derechos humanos no se puede dejar de considerar una de sus particularidades, quizá la única, que consiste en que estos tratados establecen órganos supervisores de su aplicación por los Estados parte. Desde el momento en que estos órganos tienen competencia para interpretar las disposiciones del tratado y evaluar el cumplimiento de los Estados con ellas, tienen también competencia para definir los alcances de su propia competencia y decidir sobre diversas cuestiones que puedan afectarla o limitarla, entre ellas las denuncias y los retiros de reconocimiento de competencia. En los últimos años se ha podido advertir la tendencia de estos órganos a interpretar su propia competencia de manera amplia. Sin embargo, las decisiones toma- 
das en este sentido, algunas de las cuales se han comentado anteriormente, cuestionan algunos conceptos fundamentales del derecho internacional, y no puede decirse que constituyan todavía lex lata. La práctica subsecuente de los Estados será determinante en este sentido.

La práctica de los órganos supervisores implica también un avance hacia un nuevo paradigma en el derecho internacional, que mira al ordenamiento jurídico internacional desde la perspectiva de un orden público internacional. A la base de este orden público están ciertos valores y principios fundamentales de la comunidad internacional, los cuales no dependen del consentimiento de los Estados para ser aplicados ni permiten derogaciones de ningún tipo. Los órganos supervisores parecen entender que el instrumento convencional del cual son guardianes y mecanismo de ejecución a la vez, expresa este sistema de valores comunitario, se orienta a protegerlo de manera efectiva y a asegurar su vigencia y desarrollo. En ese sentido - parece proponerse - un mecanismo tan valioso no puede estar sujeto a los principios que gobiernan los sistemas convencionales. Resta por ver cuán lejos estos órganos pueden ir con este planteamiento y si el conjunto de las relaciones internacionales está preparado para recepcionarlo.

\section{BIBLIOGRAFÍA}

CHINKIN, Christine et al., Human Rights as General norms and a State's Right to opt out. Reservations and Objections to Human Rights Conventions, Londres, British Institute of Comparative and International Law, 1997.

Eisemann, Pierre M. y Koskenniemi, Martti (eds.), The Hague, Boston, London, Académie de Droit International de la Haye, Martinus Nijhoff Publ., 2000.

GuARDIA, Ernesto de la, Derecho de los tratados internacionales, Buenos Aires, Ed. Abaco, 1997.

HAMPSON, Françoise (working paper), Sub-Commission on Prevention of Discrimination and Protection of Minorities E/CN.4/Sub.2/1999/28 28 June 1999.

HENKIn, Louis, The Age of Rights, Nueva York, Oxford, Columbia University Press, 1990.

KAMMINGA, Menno, Inter-state Accountability for Violations of Human Rights, Philadelphia, University of Pennsylvania Press, 1992. 
LOWE, Jennings y FitzMAURICE, Malgosia (ed.), Fifty Years of the International Court of Justice. Essays in Honour of Sir Robert Jennings, Cambridge University Press, 1996.

MÜller, A.; RAIC, D.; ThuRANSZKY, J. (eds.), The International Court of Justice: its Future Role after 50 Years, The Hague, Martinus Nijhoff, 1997.

PELLET, Alan, Relator especial, Segundo Informe sobre las reservas a los tratados, preparado, Comisión de Derecho Internacional, A/CN.4/ 477/Add.1, 13 de junio de 1996.

Provost, René, "Reciprocity in Human Rights and Humanitarian Law", British Yearbook of International Law, 1994.

Rosenne, Shabtai, The Law and Practice of the International Court, 1920-1996, The Hague, London, Boston, Martinus Nijhoff Publ., vol. II, 1997.

SALADO, Ana, "Estudio sobre el Comentario General número 24 del Comité de Derechos Humanos", Anuario de Derecho Internacional XIV, 1998, Universidad de Navarra.

SHIHATA, Ibrahim, The Power of the International Court to Determine its own Jurisdiction. Compétence de la compétence, The Hague, Martinus Nijhoff Publ., 1965.

SIMMA, Bruno, "From bilateralism to community interest in international law", Recueil des Cours de l'Académie de Droit International de La Haye, 1994-VI, vol. 250.

SPILIOPOUlOU, Sia, "Reservation clauses in treaties concluded within the Council of Europe", International and Comparative Law Quarterly, vol. 48, julio de 1999.

SZAFARZ, Renata, The Compulsory Jurisdiction of the International Court of Justice, Dordrecht, Boston, London, Martinus Nijhoff Publ. 1993.

Belilos v. Switzerland, European Court of Human Rights, Judgement of 29 April 1988, Series A, N 132. Ver también, Temeltasch v. Switzerland, Application N 9116/80, Report of 5 May 1982, Decisions and Reports of the European Commission of Human Rights; Loizidou $v$. Turkey (Preliminary Objections) European Court of Human Rights, Judgement of 23 March 1995 Series A N 310, p. 25.

Caso Rawle Kennedy (decisión sobre admisibilidad). Decisión del Comité de Derechos Humanos emitida a tenor del Protocolo Facultativo del Pacto Internacional de Derechos Civiles y Políticos. Comunicación N 845/1999, 31 de diciembre de 1999, CCPR/C/67/D/845/1999. 
Convención de Viena sobre el Derecho de los Tratados, 1155 United Nations Treaty Series, 331.

El efecto de las reservas sobre la entrada en vigor de la Convención Americana de Derechos Humanos (artículos 74 y 75), Opinión Consultiva OC-2/82 Corte Interamericana de Derechos Humanos, 24 de septiembre de 1982, serie A N 2; Restricciones a la pena de muerte (artículos 4.2 y 4.4. de la Convención), Opinión Consultiva OC-3/83 Corte Interamericana de Derechos Humanos, 8 de septiembre de 1983, serie A N 3.

Informe del Comité de Derechos Humanos a la Asamblea General, Actas Oficiales de la Asamblea General, 51va sesión, Suplemento 40 (A/51/40), Anexo VI.

Ireland $v$. United Kingdom, European Court of Human Rights, Series A N 25 (1978), p. 90.

Observación General 24 CCPR/C/21/Rev.1/Add. 6, 11 de noviembre de 1994, reproducido en Informe del Comité de Derechos Humanos a la Asamblea General, Actas Oficiales de la Asamblea General, 50va sesión, Suplemento 40 (A/50/40)

Observations of the Inter-American Commission on Human Rights concerning the return of the application in the case of the constitutional court v. Peru (11.760), and the jurisdiction of the Inter-American Court of Human Rights. Disponible en internet: www.cidh.org. La Comisión cita los travaux preparatoires de la Convención Europea y hace alusión a los trabajos preparatorios de la propia Convención Americana.

Preliminary Conclusions of the International Law Commission on Reservations to normative multilateral treaties including human rights treaties. Report of the International Law Commission to the General Assembly on its forty-ninth session, 12 May-18 July 1997. G.A.O.R. fifty-second session Supplement 10 (A/52/10), pp. 126-127.

Report of the ILC on the work of its forty-ninth session, 12 May 18 July 1997. General Assembly, Official Records, 52 ${ }^{\text {nd }}$ session. Supp. 10 $(A / 52 / 10)$.

Reservations to human rights treaties. Working paper submitted by Ms. Françoise Hampson pursuant to Sub-commission decision 1998/113. Reservations to the Convention on the Prevention and Punishment of the Crime of Genocide, Advisory Opinion, 28 May 1951, ICJ Reports 1951, p. 15. 
Resolución 1999/27 Subcomisión de Promoción y Protección de los Derechos Humanos. Informe de la Subcomisión de Promoción y Protección de los Derechos Humanos sobre su 51 periodo de sesiones. E/CN.4/2000/2 10 de noviembre de 1999. 